\title{
Noisy News in Business Cycles
}

\author{
By Mario Forni, Luca Gambetti, Marco LipPi, and Luca Sala*
}

We investigate the role of "noise" shocks as a source of business cycle fluctuations. To do so we set up a simple model of imperfect information and derive restrictions for identifying the noise shock in a VAR model. The novelty of our approach is that identification is reached by means of dynamic rotations of the reduced-form residuals. We find that noise shocks generate hump-shaped responses of $G D P$, consumption and investment, and account for a sizable fraction of their prediction error variance at business cycle horizons. (JEL C32, D83, E12, E23, E32, E43)

T

here has recently been a renewed interest in the old idea that business cycles could be driven by changes in the expectations about future economic conditions (early references are Pigou 1927, and Keynes 1936). The literature has focused mainly on anticipated changes in productivity, the so-called "news shocks" (Cochrane 1994). The seminal paper by Beaudry and Portier (2006) — henceforth BP - finds that news shocks account for the bulk of fluctuations in GDP and generate the pattern of comovements among macroeconomic aggregates typically observed over the cycle. ${ }^{1}$ Several papers have provided theoretical foundations for these results, by proposing models in which news shocks can drive the business cycle (see e.g., Jaimovich and Rebelo 2009, Den Haan and Kaltenbrunner 2009, Schmitt-Grohé and Uribe 2012). Key in these models is that news shocks are assumed to be observable by the agents.

One stream of the literature on news shocks has departed from the assumption of perfect information and proposed models where agents have imperfect information (Sims 2003, Beaudry and Portier 2004, Lorenzoni 2009, Angeletos and La'O 2010, among others). In the theoretical work by Lorenzoni (2009), for instance, agents base their optimal decisions on a mixture of a news on aggregate productivity and

\footnotetext{
* Gambetti: Departament d'Economia i Historia Economica, Universitat Autonoma de Barcelona, Office B3.1130, Edifici B, Bellaterra 08193, Barcelona, Spain (email: luca.gambetti@uab.cat); Forni: Dipartimento di Economia "Marco Biagi," CEPR, and RECent, Università di Modena e Reggio Emilia, Via Berengario 51, 41121 Modena, Italy (email: mario.forni@unimore.it); Lippi: Einaudi Institute for Economics and Finance, Via Sallustiana 62, 00187 Roma, Italy (email: mlippi.eief@gmail.com); Sala: Dipartimento di Economia “Ettore Bocconi”, IGIER and Baffi Center, Università Bocconi, Via Roentgen 1, 20136 Milano, Italy (email: luca.sala@ unibocconi.it). Luca Gambetti gratefully acknowledges financial support from the Ministerio de EconomÃa y Competitividad through grant ECO2015-67602-P, and the Barcelona GSE Research Network and the financial support of the Leverhulme Trust. Mario Forni acknowledges the financial support from FAR 2014 "VAR strutturali e modelli a fattori per l'analisi e la previsione del ciclo economico: teoria e applicazioni," Università di Modena e Reggio Emilia. Sala gratefully acknowledges financial support from MIUR, PRIN grant prot. 2009BL8BEF-001 "Fluttuazioni finanziarie, ciclo economico ed inflazione," and from the Baffi Center at Università Bocconi.

Go to https://doi.org/10.1257/mac.20150359 to visit the article page for additional materials and author disclosure statement(s) or to comment in the online discussion forum.

${ }^{1}$ Beaudry and Lucke (2009) and Dupaigne and Portier (2006) find similar results.
} 
noise. Though they can eventually disentangle news from noise, their current action can only rely on such a noisy signal. As a consequence, agents' expectations take time to completely adjust, and the final outcome depends on the size of the noise within the observable signal. In particular, if the signal is just noise, the economy returns to its initial state, whereas if the signal contains productivity news, the economy gradually reaches a new level of activity.

Coibion and Gorodnichenko (2012) provide evidence in line with models with informational rigidities and in contrast with rational expectations full-information models. In fact, the response of agents' forecast errors to economic shocks smoothly vanishes, a finding that is at odds with the full information rational expectation paradigm, suggesting the existence of some type of learning mechanism. Assuming that agents base their decisions on noisy information seems plausible, in particular for events — like improvements in technology — whose effects propagate slowly and therefore are not immediately revealed by observable economic variables. In the real world, agents are often uncertain about the future effects of facts that they observe. Assuming that they are not aware of the exact nature of such facts is a simple and convenient way to model this kind of "conditional" uncertainty within the rational expectations paradigm.

Models with noisy information have important consequences for empirical analysis. In particular, standard VAR methods cannot be employed (Blanchard, L'Huillier, and Lorenzoni 2013-henceforth BLL). The reason is that economic variables, by reflecting agents' behavior, can only convey information that is available to them. If agents cannot observe current structural shocks, current (and past) values of the economic time series cannot contain the relevant information to estimate such shocks. As a consequence, an econometrician will not be able to recover the structural shocks by a rotation of the VAR residuals. After all, if this were possible for the econometrician, it would be possible for the agents as well, contradicting the initial assumption. ${ }^{2}$

An equivalent formulation is that under imperfect information the structural shocks are non-fundamental with respect to agents' information set (Hansen and Sargent 1991, Lippi and Reichlin 1993, 1994). . $^{3}$

This difficulty with the application of VAR methods is perhaps the main reason why the noisy-information approach has been seldom applied in this literature. Most empirical works about the business cycle effects of news, for instance, assume that news is noise-free, i.e., that the structural shocks are observable (see e.g., Cochrane 1994; Beaudry and Portier 2006; Barsky and Sims 2011; Forni, Gambetti, and Sala 2014). However, if the information is corrupted by noise, what is interpreted as the news shock is actually a mixture of the structural shock and noise.

By contrast, BLL (2013) and Barsky and Sims (2012 - henceforth BS) assume noisy information and try to assess the role of noise ("animal spirits" in BS' terminology) in driving output fluctuations. Both papers recognize that structural VARs

\footnotetext{
${ }^{2}$ Interesting and general results about the econometric implications of linear rational expectation models with incomplete information can be found in Baxter, Graham, and Wright (2011).

${ }^{3}$ This kind of non-fundamentalness is different from the one that arises when the econometrician's information set is narrower than that of the agents. In the latter case, the problem can be solved in principle by enlarging the dataset (Forni et al. 2009, Forni and Gambetti 2014).
} 
are ill-suited and resort to direct estimation of the theoretical model. Model estimation, however, requires strong a priori restrictions on the dynamics of the structural shocks that may, in principle, have important effects on the results. In fact, the two papers reach opposite conclusions: in BLL, the noise has very large effects, whereas in BS, "animal spirits" have essentially no effects.

In this paper we provide a nonstandard structural VAR method, which allows estimation of the structural shocks and their effects under the assumption of imperfect observability. We begin the analysis by presenting a theoretical model in which agents observe the shock affecting future economic fundamentals, the long-run shock, with noise. The signal observed by the agents—-the "noisy news"- is the sum of the long-run shock and a "noise" shock. As time goes by, agents learn how much of the observed shock was noise and how much was long run. In other words, future data perfectly reveal current structural shocks. This is the key mechanism which allows us to estimate the structural shocks. Indeed, while a contemporaneous linear combination of the VAR residuals cannot deliver the correct shock, a dynamic combination involving future residuals can. A general treatment of dynamic structural VAR identification is found in Lippi and Reichlin (1994). An application to fiscal policy is shown in Mertens and Ravn (2010). Here we propose a specific identification scheme to recover the structural shocks along with the related impulse response functions within a noisy information framework. $4^{4}$

Our identification procedure is in two steps. In the first step, we use standard identification restrictions to disentangle the signal observed by the agents about future economic fundamentals and the "surprise" shock, reflecting new information coming from observation of current economic fundamentals. This step is not novel and is conceptually identical to the problem of identifying news and "surprise" shocks in the observable news-shock literature. The novelty of our approach is that we interpret the news shock as a noisy signal and the surprise shock as reflecting the realizations of past noise and long-run shocks. In a sense, we interpret news and surprise shocks as reduced-form shocks. In the second step, we use our dynamic rotation procedure to identify the underlying structural shocks, i.e., the long-run and the noise shocks, from future values of the reduced form shocks.

Using this new approach, we study the role of noise shocks as sources of business cycle fluctuations. We find that long-run and noise shocks together explain a substantial fraction of the forecast error variance of GDP, consumption, and investment. Expectations of future changes in economic fundamentals should be considered a major source of business cycle fluctuations. A sizable fraction of such fluctuations is due to noise shocks that generate hump-shaped responses of GDP, consumption and investment. The role of noise is much larger than in BS, where "animal spirits" have negligible effects, and qualitatively different from BLL, where it is found to explain a very large fraction of consumption fluctuations on impact, but a relatively small fraction of consumption variance at the three-year horizon and almost nothing of investment fluctuations.

\footnotetext{
${ }^{4}$ See also the companion paper Forni et al. (2014), where a similar news-noise setting is applied to dividends and stock prices.
} 
The remainder of the paper is organized as follows. Section I discusses the economic model and the econometric implications; Section II presents the econometric model; Section III presents the empirical evidence; Section IV concludes.

\section{Some Theory}

In this section we present a simple model where agents decide the current level of consumption on the basis of expected future economic fundamentals. Economic fundamentals are driven by a structural shock having the features of a "news" shock, i.e., its effects are delayed with respect to the time at which economic agents get information about it. Expectations are formed on the basis of a limited information set, in the sense that agents do not observe the current structural shock but only a noisy signal, the "noisy news." Precisely, agents observe the sum of the structural and the noise shock. The implication is that consumption reacts both to disturbances that actually affect future economic fundamentals and disturbances that do not have any effect.

\section{A. A Simple Model}

Let us assume that the fundamental $a_{t}$ follows the exogenous relation

$$
a_{t}=a_{t-1}+\varepsilon_{t-1}
$$

where $\varepsilon_{t}$ is a Gaussian, serially uncorrelated process affecting $a_{t}$ with a one-period delay. We refer to this shock as a "long-run" shock. At time $t$ consumers observe $\varepsilon_{t-1}$ and a noisy signal $s_{t}$ of $\varepsilon_{t}$ :

$$
s_{t}=\varepsilon_{t}+v_{t} .
$$

The noise shock $v_{t}$ is a Gaussian white noise, uncorrelated with $\varepsilon_{t}$ at all leads and lags. The variance of the signal is just the sum of the variances of the two shocks, $\sigma_{s}^{2}=\sigma_{\varepsilon}^{2}+\sigma_{v}^{2}$. In addition, agents observe the fundamental $a_{t}$, so that the consumers' information set is given by present and past values of $a_{t}$ and $s_{t}$, i.e., $\mathcal{I}_{t}=\operatorname{span}\left(a_{t-k}, s_{t-k}, k \geq 0\right)$. Given the delayed effects of the long-run shock, this information is not sufficient to distinguish the current true long-run shock from noise. At time $t+1$, however, consumers learn about the past realization of the two shocks since they observe $\varepsilon_{t}=\Delta a_{t+1}$ and therefore $v_{t}=s_{t}-\varepsilon_{t}$.

Following BLL, we assume that agents set consumption $c_{t}$ on the basis of expected long-run fundamentals; precisely,

$$
c_{t}=\lim _{j \rightarrow \infty} E\left(a_{t+j} \mid \mathcal{I}_{t}\right)
$$

Realized output, $y_{t}$, is fully demand-determined, i.e., $y_{t}=c_{t}$; employment adjusts to clear the labor market. 


\section{B. Solution and Economic Implications}

Given the process for $a_{t}$, we have $E\left(a_{t+j} \mid \mathcal{I}_{t}\right)=E\left(a_{t+1} \mid \mathcal{I}_{t}\right)$ for any $j>1$, so that

$$
c_{t}=E\left(a_{t+1} \mid \mathcal{I}_{t}\right)=a_{t}+E\left(\varepsilon_{t} \mid \mathcal{I}_{t}\right) .
$$

Since $a_{t-k}$ and $s_{t-k}$, for $k>0$, are uninformative about $\varepsilon_{t}, E\left(\varepsilon_{t} \mid \mathcal{I}_{t}\right)$ is simply the projection of $\varepsilon_{t}$ on $s_{t}$, that is

$$
E\left(\varepsilon_{t} \mid \mathcal{I}_{t}\right)=\gamma s_{t},
$$

where $\gamma=\sigma_{\varepsilon}^{2} / \sigma_{s}^{2}$. Therefore $c_{t}=a_{t}+\gamma\left(\varepsilon_{t}+v_{t}\right)$ and the change in consumption is

$$
\begin{aligned}
\Delta c_{t} & =\Delta a_{t}+\gamma \Delta\left(\varepsilon_{t}+v_{t}\right) \\
& =\gamma \varepsilon_{t}+(1-\gamma) \varepsilon_{t-1}+\gamma v_{t}-\gamma v_{t-1} .
\end{aligned}
$$

Following a long-run shock, consumption immediately jumps by $\gamma \varepsilon_{t}$ and in the second period reaches its new long-run level $c_{t-1}+\varepsilon_{t}$. Consumption reacts also to the noise shock: following a positive noise shock, consumption increases by $\gamma v_{t}$ on impact and then reverts to its initial level $c_{t-1}$ after one period. Notice that the impact responses are identical, since agents cannot distinguish between the two shocks in the current period. However, after one period, observed potential output unveils the nature of the shock and agents, recognizing it was noise, undo the initial increase by reducing consumption by $\gamma v_{t}$. While the long-run shock has a permanent effect, the noise shock has only a temporary effect.

It is instructive to compare these results with the case in which agents can observe the long-run shock without error. In this case, equation (4) implies $c_{t}=a_{t}+\varepsilon_{t}$ and

$$
\Delta c_{t}=\varepsilon_{t},
$$

so that after a long-run shock consumption jumps immediately to its new long-run level. ${ }^{5}$ Imperfect information has two implications. First, agents are more cautious in changing their consumption pattern. More precisely, for a given variance of the long-run shock, the higher the variance of noise, the smaller the contemporaneous change in consumption (recall that $\gamma=\sigma_{\varepsilon}^{2} / \sigma_{s}^{2}$ ). Second, the noise shock can generate cyclical fluctuations in consumption and output completely unrelated to economic fundamentals.

\footnotetext{
${ }^{5}$ Notice that consumption is a random walk in both cases of complete and incomplete information. To see this, consider that the first order autocovariance of $\Delta c_{t}$ in equation (5) is $\sigma_{\varepsilon}^{2} \gamma(1-\gamma)-\sigma_{v}^{2} \gamma^{2}=\sigma_{\varepsilon}^{2} \gamma-\gamma^{2}\left(\sigma_{\varepsilon}^{2}+\sigma_{v}^{2}\right)$ $=\sigma_{\varepsilon}^{2} \sigma_{\varepsilon}^{2} / \sigma_{s}^{2}-\sigma_{\varepsilon}^{4} / \sigma_{s}^{4} \sigma_{s}^{2}=0$.
} 
Let us see how quantitatively important these fluctuations can be. The total variance of consumption change is $\sigma_{\varepsilon}^{2}$. ${ }^{6}$ The contribution of the noise component is then

$$
\frac{2 \gamma^{2} \sigma_{v}^{2}}{\sigma_{\varepsilon}^{2}}=2 \frac{\sigma_{\varepsilon}^{2}}{\sigma_{s}^{4}} \sigma_{v}^{2}=\frac{2 \sigma_{\varepsilon}^{2} \sigma_{v}^{2}}{\left(\sigma_{v}^{2}+\sigma_{\varepsilon}^{2}\right)^{2}},
$$

which depends on the variance of the noise component. Let us consider the two limiting cases $\sigma_{v}^{2}=0$ and $\sigma_{v}^{2} \rightarrow \infty$. In the former case, there is no noise, so that its contribution to total variance is obviously zero. In the latter case, the signal is dominated by noise, so that it is not informative at all. Interestingly, the variance of the noise component approaches zero also in this case. The reason is that agents recognize that the signal is uninformative and do not react to it. Finally, it is easily seen that the above expression reaches its maximum when $\sigma_{v}^{2}=\sigma_{\varepsilon}^{2}$. In this case, 50 percent of the fluctuations of consumption changes are due to noise.

\section{The Failure of Standard Structural VAR Methods}

Imperfect observability of structural shocks has important econometric implications. To see this, let us rewrite the solution of the model as

$$
\left(\begin{array}{c}
\Delta a_{t} \\
\Delta c_{t} \\
s_{t}
\end{array}\right)=\left(\begin{array}{cc}
L & 0 \\
\gamma+(1-\gamma) L & \gamma-\gamma L \\
1 & 1
\end{array}\right)\left(\begin{array}{l}
\varepsilon_{t} \\
v_{t}
\end{array}\right)
$$

where $L$ is the lag operator. To simplify things, let us further assume for the moment that the econometrician can observe $s_{t}$.

First, the econometrician (just like the agents) would not be able to recover long-run and noise shocks from the present and past values of $a_{t}$ and $s_{t}$. It is easily seen from (6) that the polynomial matrix of the subsystem associated to $\Delta a_{t}$ and $s_{t}$ has determinant vanishing at zero, which implies that the corresponding bivariate MA representation is not invertible, so that a VAR representation in the structural shocks does not exist.

The econometrician could also use consumption, in addition to potential output and $s_{t}$, but still he/she would fail to recover the shock. The rank of the polynomial matrix in (6) is one for $L=0$, which means that even this "tall" representation is not invertible, or, more precisely, "non-fundamental." In other words, the two shocks cannot be obtained from present and past values of the three variables.

Non-fundamentalness is a debated issue in the structural VAR literature. Early references are Hansen and Sargent (1991) and Lippi and Reichlin (1993, 1994); more recent contributions include Giannone and Reichlin (2006); Fernández-Villaverde et al. (2007); Chari, Kehoe, and McGrattan (2008); Forni and Gambetti (2014); and Chen, Choi, and Escanciano (2017); Forni, Gambetti, and Sala (2016). Essentially, the problem is that standard SVAR methods assume that the structural shocks are

\footnotetext{
${ }^{6}$ From (5) we have $\operatorname{var}\left(\Delta c_{t}\right)=\left[\gamma^{2}+(1-\gamma)^{2}\right] \sigma_{\varepsilon}^{2}+2 \gamma^{2} \sigma_{v}^{2}=2 \gamma^{2} \sigma_{s}^{2}+(1-2 \gamma) \sigma_{\varepsilon}^{2}=2 \sigma_{\varepsilon}^{4} / \sigma_{s}^{2}-2 \sigma_{\varepsilon}^{4} / \sigma_{s}^{2}+$ $\sigma_{\varepsilon}^{2}=\sigma_{\varepsilon}^{2}$.
} 
linear combinations of the residuals obtained by estimating a VAR. If the structural MA representation of the variables included in the VAR is non-fundamental, the structural shocks are not linear combinations of such residuals, so that the method fails. ${ }^{7}$

In most of the economic literature, the structural shocks are elements of agents' information set, and non-fundamentalness may arise if the econometrician uses less information than the agents. In this case, non-fundamentalness can in principle be solved by enlarging the information set used by the econometrician (Forni et al. 2009, Forni and Gambetti 2014). But in the present setting non-fundamentalness stems from agents' ignorance and cannot be solved by adding variables to the VAR. The economic intuition is that agents' behavior cannot reveal information that agents do not have. Consumption or other variables that are the outcome of agents' decisions do not add anything to the information already contained in $a_{t}$ and $s_{t}$. More generally, in models assuming that agents cannot see the structural shocks, the structural representation is non-fundamental for whatever set of observable variables. For, if it were, agents could infer the shocks from the variables themselves, contrary to the assumption.

\section{Agents' Innovations and Structural Shocks}

As discussed above, the relevant shocks cannot be found by using standard VAR methods. Hence, a question arises: what shocks would the econometrician recover by running a VAR for potential output and the signal? To answer this question we need to find shocks that are fundamental for $\Delta a_{t}$ and $s_{t}$. Starting with

$$
\left(\begin{array}{c}
\Delta a_{t} \\
s_{t}
\end{array}\right)=\left(\begin{array}{cc}
L & 0 \\
1 & 1
\end{array}\right)\left(\begin{array}{c}
\varepsilon_{t} \\
v_{t}
\end{array}\right)
$$

we easily get the representation

$$
\left(\begin{array}{c}
\Delta a_{t} \\
s_{t}
\end{array}\right)=\left(\begin{array}{cc}
1 & L \frac{\sigma_{\varepsilon}^{2}}{\sigma_{s}^{2}} \\
0 & 1
\end{array}\right)\left(\begin{array}{c}
u_{t} \\
s_{t}
\end{array}\right),
$$

where

$$
\left(\begin{array}{l}
u_{t} \\
s_{t}
\end{array}\right)=\left(\begin{array}{cc}
L \frac{\sigma_{v}^{2}}{\sigma_{s}^{2}} & -L \frac{\sigma_{\varepsilon}^{2}}{\sigma_{s}^{2}} \\
1 & 1
\end{array}\right)\left(\begin{array}{l}
\varepsilon_{t} \\
v_{t}
\end{array}\right) .
$$

\footnotetext{
${ }^{7}$ An MA representation is fundamental if and only if the associated matrix is full column rank (i.e., the rank is equal to the number of shocks) for all $L$ with modulus less than one (see Rozanov 1967, ch. 2). This condition is slightly different from invertibility, since invertibility requires full column rank also for $L$ with unit modulus. Hence, non-fundamentalness implies non invertibility, whereas the converse is not true. When the variables are cointegrated, for instance, the MA representation of the first differences is not invertible, but nonetheless can be fundamental. In such a case, non-invertibility can be easily circumvented by resorting to structural ECM or level VAR estimation. Non-fundamentalness is a kind of non-invertibility that cannot be solved in this way.
} 
Notice that $u_{t}$ and $s_{t}$ are jointly white noise and orthogonal with variance $\sigma_{u}^{2}=\sigma_{v}^{2} \sigma_{\varepsilon}^{2} / \sigma_{s}^{2}$ and $\sigma_{s}^{2}$, respectively. ${ }^{8}$ Moreover, the determinant of the matrix in (7) is 1 , so that the MA representation (7) is fundamental, implying that $u_{t}$ and $s_{t}$ are innovations of the agents' information set. The shock $u_{t}$ can be interpreted as the "surprise" shock, and represents the new information about past structural shocks, resulting from observing present and past $\Delta a_{t}$ and $s_{t}$.

In conclusion, by running a VAR for $\Delta a_{t}$ and $s_{t}$, the econometrician would not recover the structural shocks $\varepsilon_{t}$ and $v_{t}$, but rather two shocks-surprise and signal-which are combinations of present and past values of the structural shocks. Of course, standard identification schemes would fail, since no linear combination of the two innovations at time $t$ can deliver the structural shocks.

The next question is: can the true structural shocks be recovered and how? The answer is positive, provided that the future values of the fundamental shocks are used. As already observed, after one period the observation of potential output unveils the long-run or noise nature of the signal. Indeed, representation (8) can be inverted toward the future:

$$
\left(\begin{array}{l}
\varepsilon_{t} \\
v_{t}
\end{array}\right)=\left(\begin{array}{cc}
L^{-1} & \frac{\sigma_{\varepsilon}^{2}}{\sigma_{s}^{2}} \\
-L^{-1} & \frac{\sigma_{v}^{2}}{\sigma_{s}^{2}}
\end{array}\right)\left(\begin{array}{l}
u_{t} \\
s_{t}
\end{array}\right) .
$$

The above equation shows that the structural shocks, though not recoverable as static linear combinations of the VAR residuals, can be obtained as dynamic linear combinations, involving future values. This is the key result we will use in the econometric section to identify long-run and noise shocks.

\section{E. Agents' "Learning": A Comparison with BLL and BS}

A crucial novelty of our model with respect to existing literature is the agents' learning process. For the sake of comparison, let us recast the BLL model, with minor modifications, in our notation. BLL assumes that $a_{t}$ is the sum of two components: a permanent one (which may affect $a_{t}$ on impact), driven by the shock $\varepsilon_{t}$, and a temporary one, driven by the shock $\eta_{t}$. More specifically,

$$
a_{t}=a_{t-1}+(1-\rho L)^{-1} \varepsilon_{t}+(1-L)(1-\rho L)^{-1} \eta_{t} .
$$

The signal is the same as in our model and is given by equation (2). As in our model, agents can observe $a_{t}$ and the signal $s_{t}$.

The key difference between this model and ours is the reason why observing $a_{t}$ and $s_{t}$ does not reveal the structural shocks. In our model, agents cannot see the

\footnotetext{
${ }^{8}$ To see that $u_{t}$ and $v_{t}$ are jointly white noise, observe that the covariance of $u_{t}$ and $s_{t-1}$ is $\sigma_{v}^{2} \sigma_{\varepsilon}^{2} / \sigma_{s}^{2}-\sigma_{\varepsilon}^{2} \sigma_{v}^{2} / \sigma_{s}^{2}=0$.
} 
structural shocks essentially because they have delayed effects on $a_{t}$, a feature which, combined with the noise, implies non-invertibility. On the other hand, in BLL, non-observability is due to the fact that there is also a temporary shock; that is, there are three shocks and only two dynamically independent observable variables. Similarly, the model proposed in BS for productivity and the signal has three shocks and just two variables.

This has a crucial implication. In our model, as time goes by, agents can recover past shocks exactly. In the simple version of the model described above, they learn everything after one period. In a more general setting (see Section II), agents learn gradually, but in the long run they can see past shocks without error. By contrast, in both BLL and BS, agents never learn completely the long-run or noise nature of past shocks. In both models, the MA equilibrium representation for the observable variables is rectangular, with more columns than rows. For instance, in BLL we have

$$
\left(\begin{array}{c}
\Delta a_{t} \\
s_{t}
\end{array}\right)=\left(\begin{array}{ccc}
(1-\rho L)^{-1} & 0 & (1-L)(1-\rho L)^{-1} \\
1 & 1 & 0
\end{array}\right)\left(\begin{array}{c}
\varepsilon_{t} \\
v_{t} \\
\eta_{t}
\end{array}\right)
$$

Obviously, (11) cannot be inverted, not even in the future: past shocks cannot be written as dynamic linear combinations of the observables.

Similarly, the implications of our model for VAR analysis are different from what is found in the previous literature. In the frameworks of BLL and BS, VAR methods fail because it is impossible to estimate the impulse response functions of three independent shocks - as well as the shocks themselves-with a bivariate VAR. In our framework instead, as we will show below, SVAR models can be employed successfully, as long as dynamic identification is used.

\section{The Econometric Model}

In this section, we generalize the simple model of Section D and propose our dynamic identification procedure.

Dynamic structural VAR identification is discussed in detail in Lippi and Reichlin (1994). In their more general framework, the conditions required to reach identification are very demanding. The econometrician should know the relevant unitary dynamic transformation (the so-called "Blaschke matrix"), which is characterized by the roots of the determinant of the structural representation that are smaller than one in modulus. Economic theory can hardly provide such information.

In the present setting, however, a restriction arises quite naturally from the theory: the conceptual distinction between long-run and noise shocks requires that $\Delta a_{t}$, the variable representing economic fundamentals, is not affected by noise at any lag. As a consequence, the reaction of $\Delta a_{t}$ to past signals $s_{t-1}$, and "true" long-run $\varepsilon_{t-1}$, are equal, up to a multiplicative constant, which is given by the signal-to-noise variance ratio. This in turn implies that the "wrong" roots of the structural representation are revealed by the impulse response function of $\Delta a_{t}$ to the signal $s_{t}$, which can be estimated. 


\section{A. Structural and Fundamental Representations}

Let us consider a more general specification for potential output,

$$
\Delta a_{t}=c(L) \varepsilon_{t},
$$

where $c(L)$ is a rational function in $L$ with $c(0)=0$. The structural representation becomes

$$
\left(\begin{array}{c}
\Delta a_{t} \\
s_{t}
\end{array}\right)=\left(\begin{array}{cc}
c(L) & 0 \\
1 & 1
\end{array}\right)\left(\begin{array}{l}
\varepsilon_{t} \\
v_{t}
\end{array}\right)
$$

This representation is non-fundamental, since the determinant of the MA matrix, $c(L)$, vanishes by assumption for $L=0$. This means that present and past values of the observed variables $\Delta a_{t}$ and $s_{t}$ contain strictly less information than present and past values of $\varepsilon_{t}$ and $v_{t}$.

As we have seen above, stationarity of $\Delta a_{t}$ and $s_{t}$ entails that the two variables have a fundamental representation with orthogonal innovations. Such a representation can be found as follows. Let $r_{j}, j=1, \ldots, n$, be the roots of $c(L)$, which are smaller than one in modulus and

$$
b(L)=\prod_{j=1}^{n} \frac{L-r_{j}}{1-\bar{r}_{j} L}
$$

where $\bar{r}_{j}$ is the complex conjugate of $r_{j}$. Then let us consider the representation

$$
\left(\begin{array}{c}
\Delta a_{t} \\
s_{t}
\end{array}\right)=\left(\begin{array}{cc}
\frac{c(L)}{b(L)} & \frac{c(L) \sigma_{\varepsilon}^{2}}{\sigma_{s}^{2}} \\
0 & 1
\end{array}\right)\left(\begin{array}{c}
u_{t} \\
s_{t}
\end{array}\right),
$$

where

$$
\left(\begin{array}{l}
u_{t} \\
s_{t}
\end{array}\right)=\left(\begin{array}{cc}
b(L) \frac{\sigma_{v}^{2}}{\sigma_{s}^{2}} & -b(L) \frac{\sigma_{\varepsilon}^{2}}{\sigma_{s}^{2}} \\
1 & 1
\end{array}\right)\left(\begin{array}{l}
\varepsilon_{t} \\
v_{t}
\end{array}\right) .
$$

As before, $u_{t}$ and $s_{t}$ are orthogonal innovations for the agents' information set, so that $\mathcal{I}_{t}=\operatorname{span}\left(u_{t-k}, s_{t-k}, k \geq 0\right)$.?

\footnotetext{
${ }^{9}$ To see this, observe that the determinant of the matrix in (15), i.e., $c(L) / b(L)$, vanishes only for $|L| \geq 1$ because of the very definition of $b(L)$.
} 
The relation between the fundamental shocks and the structural shock is given by

$$
\left(\begin{array}{l}
\varepsilon_{t} \\
v_{t}
\end{array}\right)=\left(\begin{array}{cc}
b(F) & \frac{\sigma_{\varepsilon}^{2}}{\sigma_{s}^{2}} \\
-b(F) & \frac{\sigma_{v}^{2}}{\sigma_{s}^{2}}
\end{array}\right)\left(\begin{array}{l}
u_{t} \\
s_{t}
\end{array}\right)
$$

where $F$ is the forward operator, i.e., $F=L^{-1} \cdot 10$ As in the previous section, the structural shock depends on future fundamental innovations, with the difference that here the long-run and noise shocks contained in the signal get unveiled in the long run, rather than after one period.

We further assume that the signal $s_{t}$ is not observed by the econometrician, but there is one observable variable, $z_{t}$, which reveals the signal. In principle, such a variable may depend on both $s_{t}$ and $u_{t}$. Therefore we can write the representation of $\Delta a_{t}$ and $z_{t}$ as

$$
\left(\begin{array}{c}
\Delta a_{t} \\
z_{t}
\end{array}\right)=\left(\begin{array}{ll}
a_{11}(L) & a_{12}(L) \\
a_{21}(L) & a_{22}(L)
\end{array}\right)\left(\begin{array}{c}
u_{t} / \sigma_{u} \\
s_{t} / \sigma_{s}
\end{array}\right)=\left(\begin{array}{cc}
\frac{c(L) \sigma_{u}}{b(L)} & \frac{c(L) \sigma_{\varepsilon}^{2}}{\sigma_{s}} \\
d(L) \sigma_{u} & f(L) \sigma_{s}
\end{array}\right)\left(\begin{array}{c}
u_{t} / \sigma_{u} \\
s_{t} / \sigma_{s}
\end{array}\right)
$$

where, following the usual econometric convention, the shocks are normalized to have unit variance. ${ }^{11}$

Moreover,

$$
\left(\begin{array}{c}
u_{t} / \sigma_{u} \\
s_{t} / \sigma_{s}
\end{array}\right)=\left(\begin{array}{cc}
b(L) \frac{\sigma_{v}}{\sigma_{s}} & -b(L) \frac{\sigma_{\varepsilon}}{\sigma_{s}} \\
\frac{\sigma_{\varepsilon}}{\sigma_{s}} & \frac{\sigma_{v}}{\sigma_{s}}
\end{array}\right)\left(\begin{array}{c}
\varepsilon_{t} / \sigma_{\varepsilon} \\
v_{t} / \sigma_{v}
\end{array}\right)
$$

so that the structural representation is

$$
\left(\begin{array}{c}
\Delta a_{t} \\
z_{t}
\end{array}\right)=\left(\begin{array}{cc}
c(L) \sigma_{\varepsilon} & 0 \\
f(L) \sigma_{\varepsilon}+b(L) d(L) \frac{\sigma_{\varepsilon} \sigma_{v}^{2}}{\sigma_{s}^{2}} & f(L) \sigma_{v}-b(L) d(L) \frac{\sigma_{v} \sigma_{\varepsilon}^{2}}{\sigma_{s}^{2}}
\end{array}\right)\left(\begin{array}{c}
\varepsilon_{t} / \sigma_{\varepsilon} \\
v_{t} / \sigma_{v}
\end{array}\right)
$$

\section{B. Dynamic Identification}

Dynamic identification of the structural shocks is done in two parts. First we estimate and identify the "reduced-form" representation (18). This first step is conceptually identical to the estimation of a standard, noise-free, news shock (which corresponds to our signal). Second, we identify (19): here is the novelty of our

\footnotetext{
${ }^{10}$ Observe that $1 / b(L)=b(F)$.

${ }^{11}$ Observe that the above representation is not necessarily fundamental, since the determinant of the MA matrix depends on $d(L)$ and $f(L)$. In order to have fundamentalness, $z_{t}$ has to be sufficiently informative to reveal $s_{t}$. In the reminder of this section we assume fundamentalness of (18); in the empirical section we will test for this property.
} 
approach. Given the estimates of (18) and (19), an estimate of representation (20) immediately follows.

More specifically, the steps are the following:

- Estimate an unrestricted VAR for $\Delta a_{t}$ and $z_{t}$ and compute the MA representation.

- Impose that $a_{12}(0)=0$. This condition implies that $s_{t}$ does not affect $\Delta a_{t}$ and comes from the theoretical restriction $c(0)=0$. In the bivariate case, this is sufficient to identify the two fundamental shocks $u_{t}$ and $s_{t}$ and obtain an estimate of all the elements of the matrix of the impulse response functions of (18).

- Let us call $\hat{a}_{12}(L)$ the estimate of $c(L) \sigma_{\varepsilon}^{2} / \sigma_{s}$ (see equation (18)). An estimate $\hat{b}$ $(L)$ of $b(L)$ can be obtained as follows. Compute the roots of $\hat{a}_{12}(L)$ and select the roots that are smaller than one in modulus (of course, one out of these roots will be zero by construction because of the identifying assumption $c(0)=0$ of step (i)). Using the roots that are smaller than one in modulus, estimate the polynomial $b(L)$ in equation (14).

- Let $\hat{a}_{11}(L)$ be the estimate of $a_{11}(L)$, i.e., our estimate of $c(L) \sigma_{u} / b(L)$, and observe that $b(1)=1$. Estimate $\sigma_{\varepsilon} / \sigma_{v}$ as the ratio ${ }^{12}$

$$
\frac{\hat{a}_{12}(1)}{\hat{a}_{11}(1)} \text {. }
$$

- Using the property that: $\sigma_{v}^{2} / \sigma_{s}^{2}+\sigma_{\varepsilon}^{2} / \sigma_{s}^{2}=1, \widehat{\sigma_{\varepsilon} / \sigma_{s}}$ and $\widehat{\sigma_{v} / \sigma_{s}}$ are obtained as $\sin \left(\arctan \left(\widehat{\sigma_{\varepsilon} / \sigma_{v}}\right)\right)$ and $\cos \left(\arctan \left(\widehat{\sigma_{\varepsilon} / \sigma_{v}}\right)\right)$, respectively.

These five steps give the estimates of all the elements of representations (18) and (19) and consequently of all the elements in (20).

The (normalized) structural shocks $\varepsilon_{t} / \sigma_{\varepsilon}$ and $v_{t} / \sigma_{v}$ can be estimated by inverting equation (19). Since the determinant of the matrix in (19) $1 / b(L)=b(F)$ involves future values of $u_{t}$ and $s_{t}$, the structural shocks cannot be estimated consistently at the end of the sample. This is in line with the assumption that neither the agents nor the econometrician can see the current values of the structural shocks. However, in the middle of the sample the future is known and (17) can in principle provide reliable estimates of $\varepsilon_{t} / \sigma_{\varepsilon}$ and $v_{t} / \sigma_{v}$. Such estimates can be used in combination with the corresponding response functions to decompose the series into the long-run and noise components and assess their importance in terms of explained variance.

Let us note that the theoretical restrictions appearing in the first line of representation (18) are only partially exploited for identification and therefore can be used for testing. Such restrictions entail that in the structural representation (20) the impulse response function of $\Delta a_{t}$ to a noise shock be identically zero, an hypothesis that can be easily verified by looking at the confidence bands. ${ }^{13}$

\footnotetext{
${ }^{12}$ In practice, we compute the cumulated long-run effects as the effects at 40 quarters.

${ }^{13}$ The identification restrictions (i) - (v) impose a zero impact effect and a zero long-run cumulated effect; but between lag 0 and the maximal lag the impulse response function can be significantly different from zero.
} 


\section{Multivariate Specifications}

Let us now consider a multivariate extension of the bivariate model described so far. Variations of this model will be used in the empirical section to investigate the role of noisy news in generating cyclical fluctuations.

Let $\mathbf{w}_{t}$ be an $n-2$-dimensional vector of additional stationary variables. In order to have a square system, it is convenient to assume that there are also $n-2$ additional shocks representing for instance sources of business cycle fluctuations unrelated to noise, like monetary or fiscal policy shocks. To be as general as possible, let us assume that such shocks may affect $a_{t}$. Equation (1) becomes

$$
\Delta a_{t}=c(L) \varepsilon_{t}+\mathbf{g}(L) \mathbf{e}_{t},
$$

where $\mathbf{e}_{t}$ is an $n$-2-dimensional white noise vector with identity variance covariance matrix, orthogonal to $\varepsilon_{t}$ at all leads and lags, and $\mathbf{g}(L)$ is an $n$-2-dimensional row vector of rational functions in $L$. Moreover, we assume for simplicity that agents can observe $e_{t}$.

Under these assumptions, the "innovation" representation can be written as

$$
\left(\begin{array}{c}
\Delta a_{t} \\
z_{t} \\
\mathbf{w}_{t}
\end{array}\right)=\left(\begin{array}{ccc}
\frac{c(L) \sigma_{u}}{b(L)} & \frac{c(L) \sigma_{\varepsilon}^{2}}{\sigma_{s}} & \mathbf{g}(L) \\
d(L) \sigma_{u} & f(L) \sigma_{s} & \mathbf{p}(L) \\
\mathbf{q}(L) & \mathbf{h}(L) & \mathbf{m}(L)
\end{array}\right)\left(\begin{array}{c}
u_{t} / \sigma_{u} \\
s_{t} / \sigma_{s} \\
\mathbf{e}_{t}
\end{array}\right),
$$

where $\mathbf{p}(L), \mathbf{q}(L), \mathbf{h}(L)$, and $\mathbf{m}(L)$ are conformable vectors and matrices of rational functions in $L .{ }^{14}$

Equation (22) is not identified. The condition that the long-run shock does not affect $a_{t}$ on impact, i.e., $c(0)=0$, is no longer sufficient in the multivariate setting. We need additional restrictions to identify $u_{t}$ and $s_{t}$. Once $u_{t}$ and $s_{t}$ are identified, the upper left two-dimensional subsystem of (22) reduces to the bivariate case. The structural shocks $\varepsilon_{t}$ and $v_{t}$ and the associated impulse response functions can then be obtained by using the method described in the previous subsection. In particular, the structural shocks are obtained via equation (19), whereas the impulse response functions are obtained by post-multiplying the matrix appearing in (22) by

$$
\left(\begin{array}{ccc}
b(L) \frac{\sigma_{v}}{\sigma_{s}} & -b(L) \frac{\sigma_{\varepsilon}}{\sigma_{s}} & \mathbf{0}^{\prime} \\
\frac{\sigma_{\varepsilon}}{\sigma_{s}} & \frac{\sigma_{v}}{\sigma_{s}} & \mathbf{0}^{\prime} \\
\mathbf{0} & \mathbf{0} & \mathbf{I}_{n-2}
\end{array}\right),
$$

where $\mathbf{0}$ denotes the $n$-2-dimensional column vector of zeros.

\footnotetext{
${ }^{14}$ Again, we assume fundamentalness of such representation.
} 


\section{Identification Issues}

As should be clear from the above discussion, the identification problem in the multivariate setting reduces to identification of $u_{t}$ and $s_{t}$. As for $u_{t}$, we assume that this shock is the only one affecting $a_{t}$ on impact, i.e., $\mathbf{g}(0)=\mathbf{0}, c(0)=0$. This is the restriction used to identify the "surprise" shock in Barsky and Sims (2011) and Forni, Gambetti, and Sala (2014). Indeed, if $e_{t}$ includes sources of business-cycle fluctuations like monetary or fiscal policy shocks, $a_{t}$ should be largely unaffected by them at least contemporaneously.

As for $s_{t}$, following Forni et al. (forthcoming), we assume a Cholesky scheme, where $s_{t}$ is the shock associated with $z_{t}$. Clearly, results depend heavily on the choice of $z_{t}$ and the position of $z_{t}$ in the Cholesky ordering. Let us discuss these two issues in order. First, the choice of $z_{t}$. Such variables should be heavily affected on impact by news about future economic activity. As documented by Beaudry and Portier (2006), stock prices are good candidates in this respect and we use them in our benchmark specification. The Michigan sentiment index is another interesting candidate (Barsky and Sims 2012) and we use it in a robustness check.

As for the ordering, $z_{t}$ should ideally be ordered before variables like consumption, investment and GDP, since noisy news may in principle affect consumption and investment decisions on impact. On the other hand, the proxy used for $z_{t}$ may be affected on impact by short-run sources of variation unrelated to technology and noise shocks. Stock prices, for instance, are likely affected by interest rates and monetary policy. If the estimated signal is corrupted by such sources of fluctuations, they might be spuriously interpreted as noise and the business-cycle effects of noise might be overstated. Hence, we split the variables in $\mathbf{w}_{t}$ into two vectors, $\mathbf{w}_{1 t}$ and $\mathbf{w}_{2 t}$, and impose the ordering $\left[\Delta a_{t}, \mathbf{w}_{1 t}, z_{t}, \mathbf{w}_{2 t}\right]$. The role of $\mathbf{w}_{1 t}$, the federal funds rate in the benchmark specification, is precisely to purge the signal from short-run fluctuations unrelated to noise.

The above ordering implies that (i) $\mathbf{w}_{1 t}$ is not affected by $s_{t}$ on impact and (ii) $z_{t}$ is not affected on impact by the $\operatorname{shock}(\mathrm{s})$ associated with $\mathbf{w}_{2 t}$. The plausibility of (i) and (ii) depends on the proxies chosen for $\mathbf{w}_{1 t}$ and $z_{t}$. Let us discuss them briefly with reference to the variables used in our benchmark specification, namely stock prices and the federal funds rate. Assuming that the federal funds rate follows a standard Taylor rule, (i) is plausible, provided that news have no contemporaneous effects on GDP and inflation. This condition can in principle be checked empirically, since $\mathbf{w}_{2 t}$ is ordered after $z_{t} \cdot{ }^{15}$ Condition (ii) implies that stock prices only react on impact to fundamentals, the noise and the interest rate. Indeed, stock prices are likely to react to risk premia, too. For this reason, in the robustness section we use an interest rate spread in place of, and in addition to, the federal funds rate.

Alternative identification strategies have been used in the literature to identify the news shock. In Forni, Gambetti, and Sala (2014), $s_{t}$ is identified as the linear combination of the $n-1$ shocks orthogonal to $u_{t}$ having maximal effect on $a_{t}$ at a given long-run horizon (ten years). Barsky and Sims (2011), uses a similar

\footnotetext{
${ }^{15}$ We show below that GDP does not react significantly on impact to noisy news. The same result holds for specifications including inflation, not shown here.
} 
approach, by maximizing the explained variance of $a_{t}$. These procedures, while not requiring the zero restrictions (i) and (ii), rely on the estimated long-run effects of all shocks, which may be inaccurate. As a robustness check, we use the method of Forni, Gambetti, and Sala (2014) (see Section IV).

\section{E. Simulations}

In order to assess the reliability of our approach, we generate artificial data from a fully fledged DSGE model. The model is the one studied in BLL (2013) and is a New-Keynesian model featuring habit persistence, variable capital utilization, sticky prices and sticky wages. ${ }^{16}$ We perform different simulations.

Simulation 1.-We assume $c(L)=L^{4}$ so that the process for the fundamental becomes $\Delta a_{t}=\varepsilon_{t-4}$. We also assume $\mathbf{g}(L)=0, d(L)=1+0.2 L, f(L)=1+0.8 L$, and $\mathbf{p}(L)=\mathbf{1} \times 0.5 L$, where $\mathbf{1}$ is a vector of ones of either five or four elements. We generate 500 observations of a vector of seven artificial series, $\mathbf{x}_{t}=\left[a_{t} z_{t} \mathbf{w}_{t}^{\prime}\right]^{\prime}$, where $\mathbf{w}_{t}=\mathbf{w}_{2 t}$ includes consumption (C), output (Y), investment (I), hours worked, and inflation, and for simplicity we ignore $\mathbf{w}_{1 t}$. The variable $z_{t}$ is constructed from equations (22) and (23) with the above specified polynomials. With the simulated series, we estimate a $\operatorname{VAR}(8)$ with $\mathbf{x}_{t}$ and apply our identification scheme. In the first step, $u_{t}$ and $s_{t}$ are identified by imposing a standard recursive ordering. We repeat the procedure 1,000 times. Figure 1 plots results. The solid line is the impulse response of the model, the dashed line is the average across simulations and the gray area represents the 90 percent confidence bands of the simulation. Despite the visible downward bias the identification approach captures fairly well the true impulse response functions, the solid line lying always within the bands.

Simulation 2.-The second simulation is identical to the previous one, but we use only six shocks to generate the series because we switch off the noise shock. The $\operatorname{VAR}(8)$ is estimated using six variables: $a_{t}, z_{t}$, and $\mathbf{w}_{t}$ which now includes consumption (C), output (Y), investment (I), and hours worked. Figure 2 plots results. The bands for the noise shock always include the zero line, correctly capturing the absence of noise.

Simulation 3.-To check for the robustness of our procedure to the introduction of an additional unobserved shock affecting fundamentals, we assume $\Delta a_{t}=$ $\varepsilon_{t-4}+\delta_{t}$, where $\delta_{t}$ is a Gaussian iid shock. The variance of $\delta_{t}$ is set to $2 \sigma_{\varepsilon}^{2}$. With this model, agents cannot fully learn the past values of $\varepsilon_{t}$, similarly to BLL (2013) and BS (2011). The VAR(8) is estimated by using seven variables: $a_{t}, z_{t}$, consumption (C), output (Y), investment (I), hours worked, and inflation. Figure 3 plots results. The inclusion of the additional shock affects mainly the impulse response functions of the long-run shock, which are now slightly overestimated. The impulse response functions of the noise shock are well estimated.

\footnotetext{
${ }^{16}$ We set parameter values equal to the posterior mean in BLL (2013). In particular, $\sigma_{\varepsilon}=1.19, \sigma_{v}=1.47$. We have also experimented by changing few parameters. Results are robust.
} 

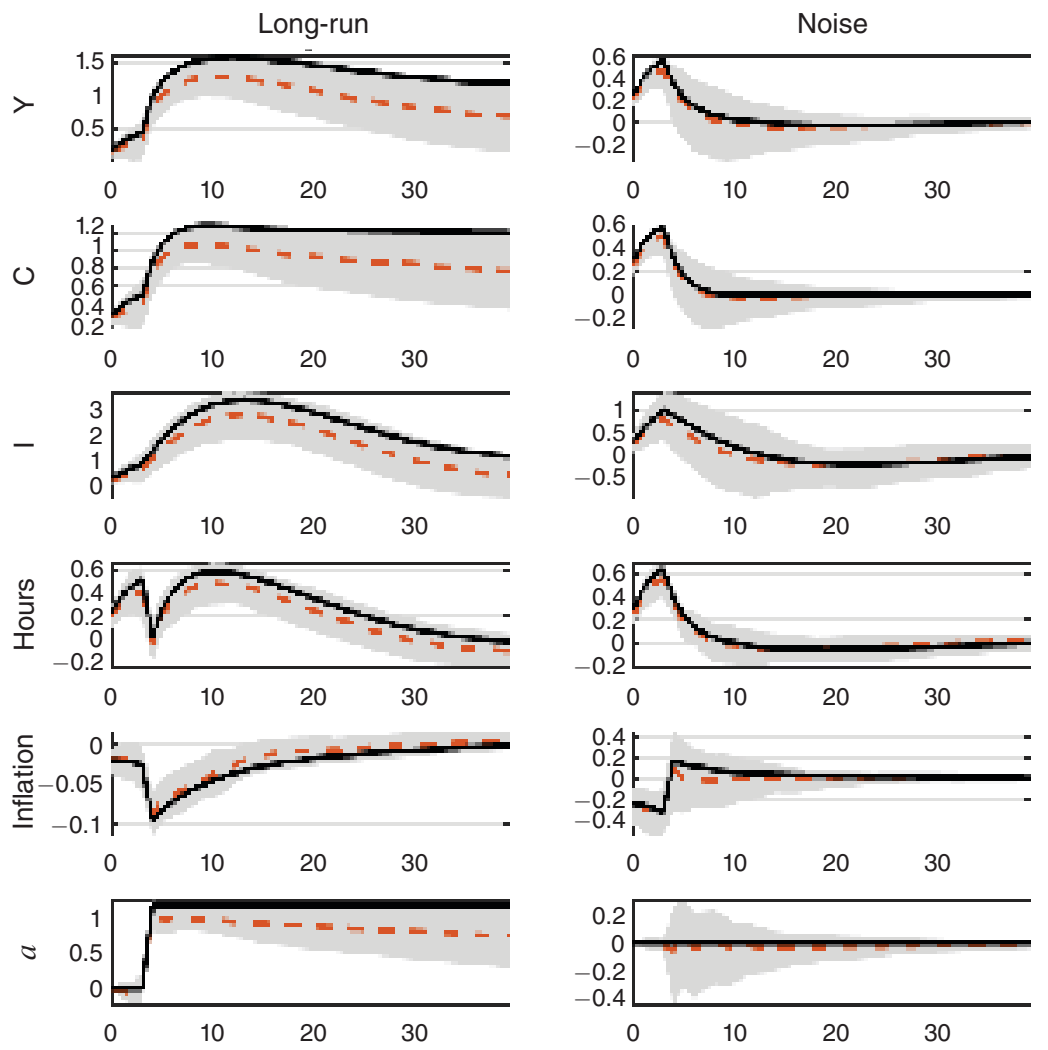

Figure 1. Impulse-Response Functions, Simulation 1

Notes: Impulse response functions to long-run (left column) and noise (right column) shocks in simulation 1. Solid line: point estimate. Dashed line: average across 500 simulations. Gray area: 90 percent confidence bands.

All in all, our procedure seems to be successful in identifying the effects of the structural shocks.

\section{Evidence}

In this section, we apply the methods described above to study the role of long-run and noise shocks as sources of business cycle fluctuations. The main conclusion is that both shocks explain a sizable fraction of the forecast error variance of GDP, consumption, and investment at business cycle horizons.

\section{A. Data}

The first step in our empirical analysis is to choose two series for $a_{t}$ and $z_{t}$. Recall that the former is the variable representing economic fundamentals, which is unaffected by noise, while the latter is a variable revealing the signal $s_{t}$.

We use two VAR specifications, corresponding to two different choices of $a_{t}$. In the former, $a_{t}$ is the log of US potential GDP from the CBO (GDPPOT), divided by 

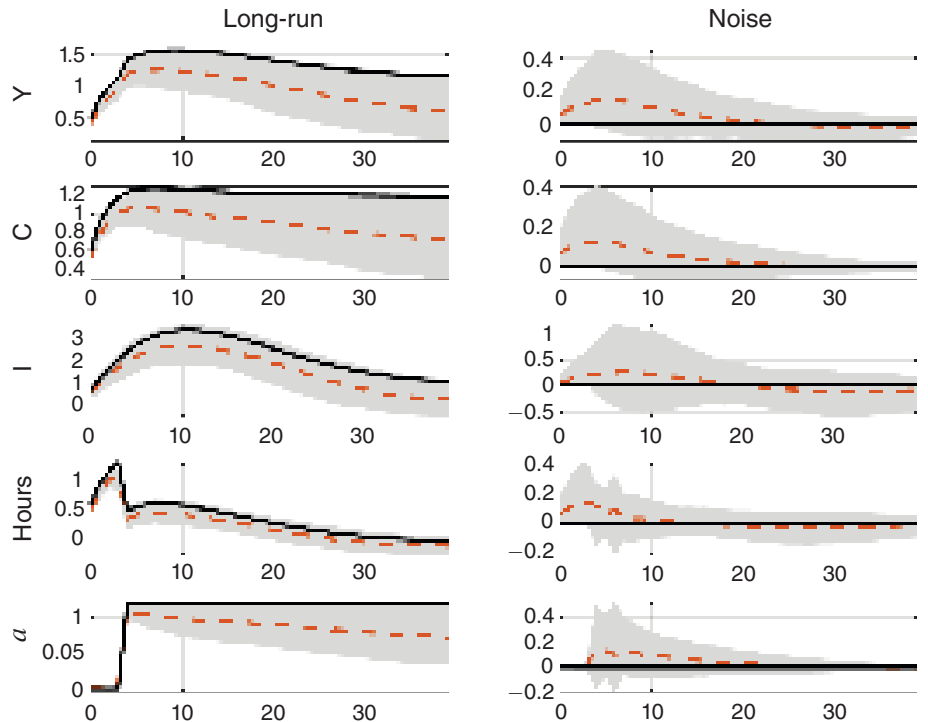

Figure 2. Impulse-Response Functions, Simulation 2

Notes: Impulse response functions to long-run (left column) and noise (right column) shocks in simulation 2. Solid line: point estimate. Dashed line: average across 500 simulations. Gray area: 90 percent confidence bands.
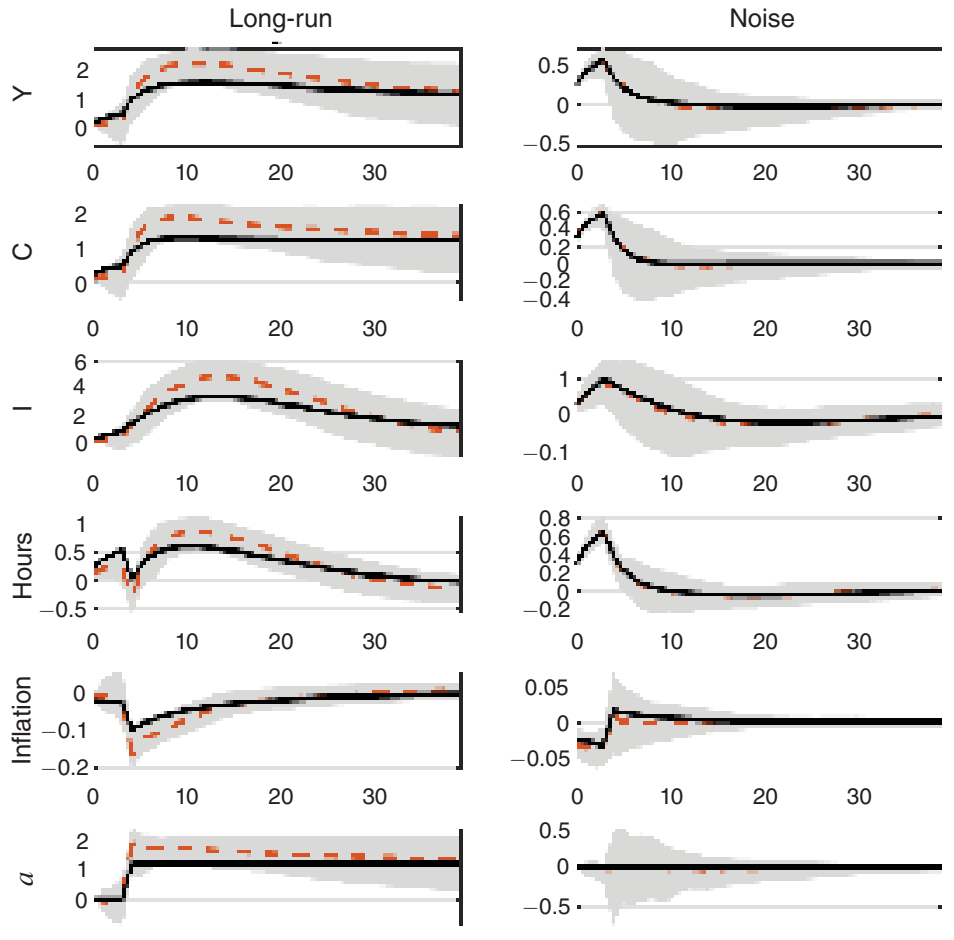

Figure 3. Impulse-Response Functions, Simulation 3

Notes: Impulse response functions to long-run (left column) and noise (right column) shocks in simulation 3. Solid line: point estimate. Dashed line: average across 500 simulations. Gray area: 90 percent confidence bands. 
population aged 16 years or more (civilian noninstitutional population). In the latter, $a_{t}$ is total factor productivity, corrected for capacity utilization and cumulated to get level figures (TFP). ${ }^{17}$

Following Beaudry and Portier (2006), we use stock prices (the Standard and Poor's index of 500 stocks) ${ }^{18}$ to represent $z_{t}$. In a robustness exercise, we use an alternative variable, i.e., the expected business conditions within the next five years (E5Y), which is a component of the consumer confidence index from the Michigan University Consumer Survey, extensively discussed in BS (2011).

Next, we specify the variables in $\mathbf{w}_{t}=\left(\mathbf{w}_{1 t}^{\prime} \mathbf{w}_{2 t}^{\prime}\right)$. As for $\mathbf{w}_{1 t}$, we take the federal funds rate, in order to purge the signal from stock price variations due to interest rates and monetary policy. In a robustness exercise, we use as an alternative control variable the spread between a risky interest rate (BAA corporate bonds) and the ten-year treasury bond. ${ }^{19}$ As for $\mathbf{w}_{2 t}$, since we are interested in evaluating the business-cycle effects of long-run and noise shocks, we take real GDP, real consumption, obtained as the sum of consumption of nondurables and services, and real investment, obtained as the sum of private investment and durable consumption. All these variables are divided by civilian noninstitutional population and taken in logs.

Finally, in order to test for fundamentalness of representation (22), we use the principal components from a large dataset of macroeconomic variables. Such variables, along with the corresponding transformations, are reported in the online Appendix. The time span of our sample is 1960:I-2010:IV.

\section{B. VAR Specification and the Fundamentalness Test}

Summing up, we have two six-variable specifications. Specification I includes GDPPOT, the federal funds rate (FFR), stock prices (S\&P500), real GDP (GDP), real consumption (CONS) and real investment (INV). Specification II includes TFP, FFR, S\&P500, GDP, CONS, and INV. To avoid potential cointegration problems we estimate the VARs in levels. In both cases we include four lags.

As explained in Section III, identification of $u_{t}$ and $s_{t}$ is obtained by imposing a standard Cholesky scheme, with the above ordering, so that $u_{t}$ is the first shock and $s_{t}$ is the third one. The structural representation is obtained by following the procedure explained in Section II. Before identifying shocks, impulse response functions from the VAR in levels for the non-stationary variables have been first-differenced.

As a first step, we test for fundamentalness of representation (22) as suggested in Forni and Gambetti (2014). The idea underlying their method is simple: if representation (22) is fundamental, i.e., if the variables used in the VAR span the information set of the agents, then the estimated shocks (surprise and $s_{t}$ ) must be orthogonal to all available past information. The same orthogonality necessary condition holds a fortiori for the structural shocks, which are a linear combination of present and future values of $u_{t}$ and $s_{t}$.

\footnotetext{
${ }^{17}$ See Basu, Fernald, and Kimball (2006).

${ }^{18}$ This is obtained from the monthly S\&P500 index provided by Datastream. We converted the series in quarterly figures by taking simple averages. The resulting series is taken in logs.

${ }^{19}$ Monthly figures are aggregated across time to get quarterly data.
} 
TABle 1 -Fundamentalness Test

\begin{tabular}{|c|c|c|c|c|c|c|c|c|c|c|}
\hline \multirow[b]{3}{*}{ Shock } & \multirow[b]{3}{*}{ Lags } & \multicolumn{9}{|c|}{ Number of principal components } \\
\hline & & \multicolumn{3}{|c|}{ Specification I } & \multicolumn{3}{|c|}{ Specification II } & \multicolumn{3}{|c|}{ Bivariate VAR } \\
\hline & & 2 & 4 & 6 & 2 & 4 & 6 & 2 & 4 & 6 \\
\hline \multirow[t]{2}{*}{ Surprise } & 2 & 0.84 & 0.84 & 0.77 & 0.99 & 0.94 & 0.96 & 0.64 & 0.77 & 0.66 \\
\hline & 4 & 0.97 & 0.98 & 0.85 & 0.38 & 0.67 & 0.87 & 0.87 & 0.89 & 0.50 \\
\hline \multirow[t]{2}{*}{ Signal } & 2 & 0.81 & 0.29 & 0.37 & 0.74 & 0.40 & 0.41 & 0.53 & 0.05 & 0.08 \\
\hline & 4 & 0.88 & 0.35 & 0.11 & 0.68 & 0.31 & 0.18 & 0.40 & 0.07 & 0.02 \\
\hline \multirow[t]{2}{*}{ Long-run } & 2 & 0.98 & 0.94 & 0.68 & 0.57 & 0.40 & 0.60 & 0.75 & 0.87 & 0.34 \\
\hline & 4 & 0.95 & 0.48 & 0.28 & 0.89 & 0.40 & 0.14 & 0.40 & 0.19 & 0.05 \\
\hline \multirow[t]{2}{*}{ Noise } & 2 & 0.95 & 0.38 & 0.51 & 0.21 & 0.43 & 0.46 & 0.98 & 0.04 & 0.11 \\
\hline & 4 & 0.98 & 0.68 & 0.54 & 0.35 & 0.79 & 0.61 & 0.97 & 0.22 & 0.29 \\
\hline
\end{tabular}

Notes: Results of the fundamentalness test for Specifications I and II and the bivariate VAR with TFP and stock prices only. Each entry of the table reports the $p$-value of the $F$-test in a regression of the shock on 2 and 4 lags of the first differences of the first $j$ principal components, $j=2,4,6$.

To represent available macroeconomic information we take the principal components of the US macroeconomic dataset reported in the online Appendix. Table 1 reports the $p$-values of the $F$-test of the regression of the estimated shocks on 2 and 4 lags of the first $j$ principal components, with $j=1, \ldots, 6$. The null of orthogonality is never rejected for both specifications.

For comparison, we report the corresponding results for the VAR including only TFP and S\&P500 in the right panel of the table. For the bivariate specification, orthogonality of both the signal and the long-run shock is rejected, indicating that the two series do not convey enough information to recover the structural shocks.

\section{Impulse Response Functions}

Figures 4 and 5 depict the impulse response functions of the six variables to surprise and signal shocks obtained with Specification I. Shaded areas represent confidence bands at the 90 percent level (light gray) and the 68 percent level (dark grey), constructed using the method proposed by Kilian, 1998. As expected, the signal shock anticipates significantly potential GDP. Moreover, it has a positive and significant impact effect on consumption, investment, and GDP, reaching its maximum at the one-year horizon. Afterward, the effect declines, while, at the same time, the effect of surprise increases and becomes significant. As agents learn about the past long-run and noise shocks by looking at available information, they partially correct their previous response to the signal.

Figure 6 reports the impulse response functions of potential GDP and stock prices to long-run and noise shocks. The noise, as predicted by the model, has no effects on potential output at all horizons. On the contrary, the response of potential output to the long-run shock increases steadily, after a zero initial effect, reaching its new long-run level after about ten years. The federal funds rate reacts positively to the noise shock, consistently with the positive effect on GDP (see below). As for stock prices, both long-run and noise shocks have a significant impact effect, but the effect of noise is larger, reflecting the estimate of $\sigma_{\varepsilon} / \sigma_{s}$, which is 0.57 (as against 0.82 of $\left.\sigma_{v} / \sigma_{s}\right)$. Hence, news and noise shocks are approximately the same size, which is consistent with sizable business-cycle effects of noise. 

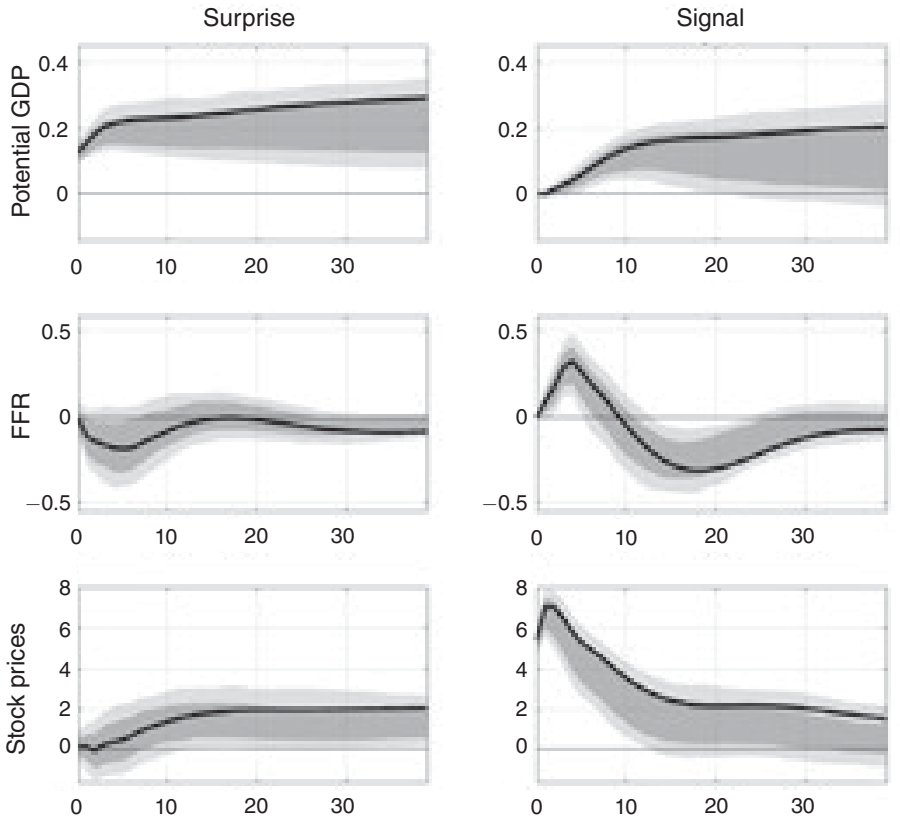

Figure 4. Impulse-Response Functions to Surprise and Signal Shocks, Specification I

Notes: Impulse response functions to surprise (left column) and signal (right column) shocks with Specification I. Solid line: point estimate. Light gray area: 90 percent confidence bands. Dark gray area: 68 percent confidence bands.
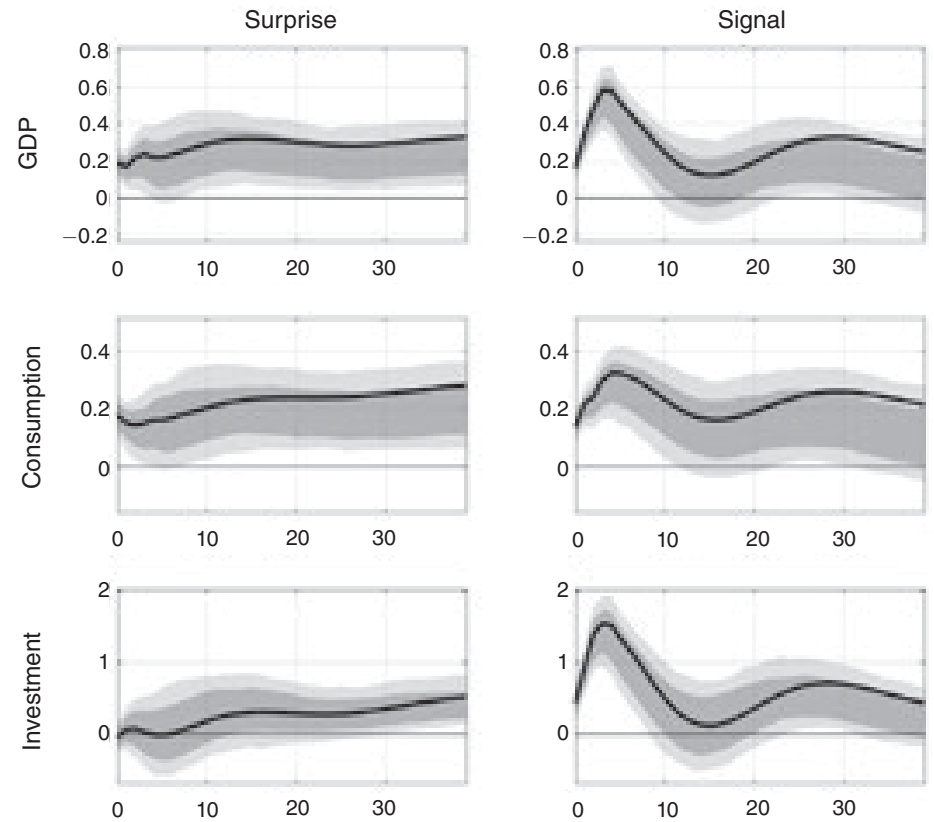

Figure 5. Impulse-Response Functions to Surprise and Signal Shocks, Specification I

Notes: Impulse response functions to surprise (left column) and signal (right column) shocks with Specification I. Solid line: point estimate. Light gray area: 90 percent confidence bands. Dark gray area: 68 percent confidence bands. 

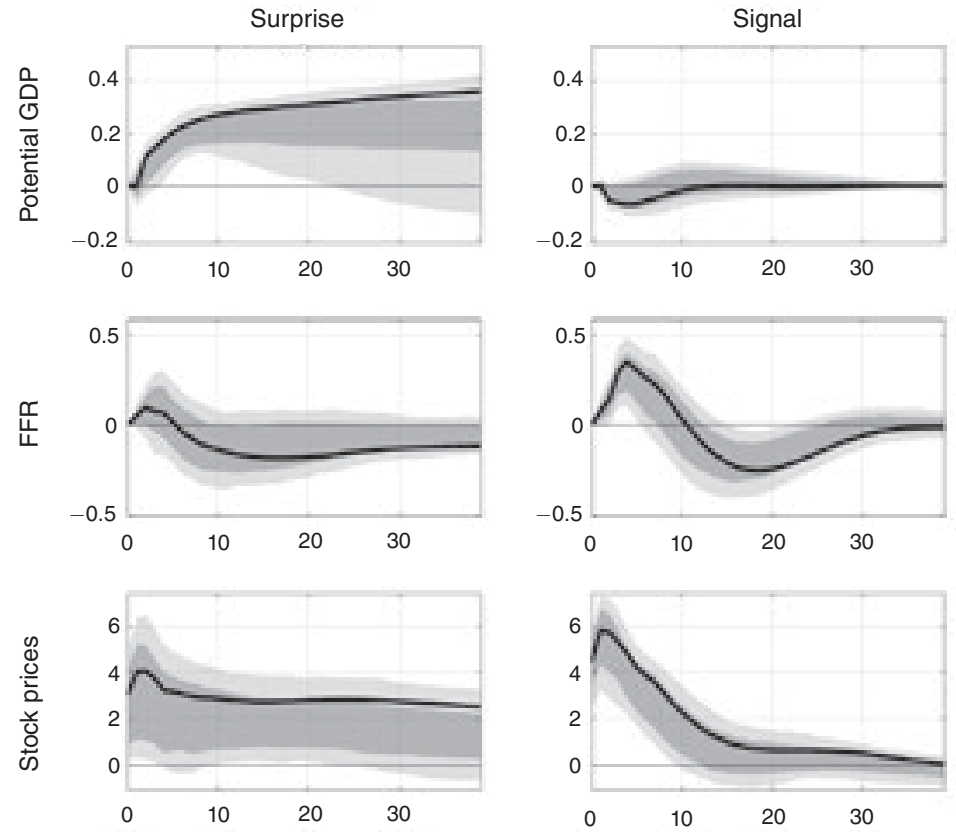

Figure 6. Impulse-Response Functions to Long-Run and Noise Shocks, Specification I

Notes: Impulse response functions to long-run (left column) and noise (right column) shocks with Specification I. Solid line: point estimate. Light gray area: 90 percent confidence bands. Dark gray area: 68 percent confidence bands.

Next we turn our attention to GDP, consumption, and investment (Figure 7). The responses of the three variables have similar shapes. In the case of the noise shock, the responses are hump-shaped with a relatively small, though significant, impact effect; they reach a maximum after about one year, then decline approaching zero after about three years. On the contrary, the responses to genuine long-run shocks are permanent. As predicted by the model, noise shocks spur a wave of private consumption and investment which vanishes once economic agents realize that the signal was just noise.

Figures 8, 9, 10, and 11 report the impulse response functions obtained with Specification II, with TFP in place of GDPPOT. A noticeable result is that the response of TFP to the signal is negative in the short-run (Figure 8), upper right panel), despite the large, positive short-run effect of the signal on GDP (Figure 9, upper right panel), similar to the evidence in Beaudry, Nam, and Wang (2011). However, as expected, the signal anticipates a positive and significant growth of TFP, GDP, consumption, and investment in the long run.

Figure 10 shows that the noise shock has a sizable effect on TFP, though the effect is not statistically significant. The impact effect of noise on stock prices is now smaller than the one of genuine news, reflecting a different signal-to-noise ratio: $\sigma_{\varepsilon} / \sigma_{s}$ is now 0.85 as against 0.53 of $\sigma_{v} / \sigma_{s}$. Again, the two shocks are similar in size, even if their relative importance is reversed.

The effect of long-run and noise shocks on GDP, consumption, and investment reported in Figure 11 are qualitatively similar to those of Specification I. 

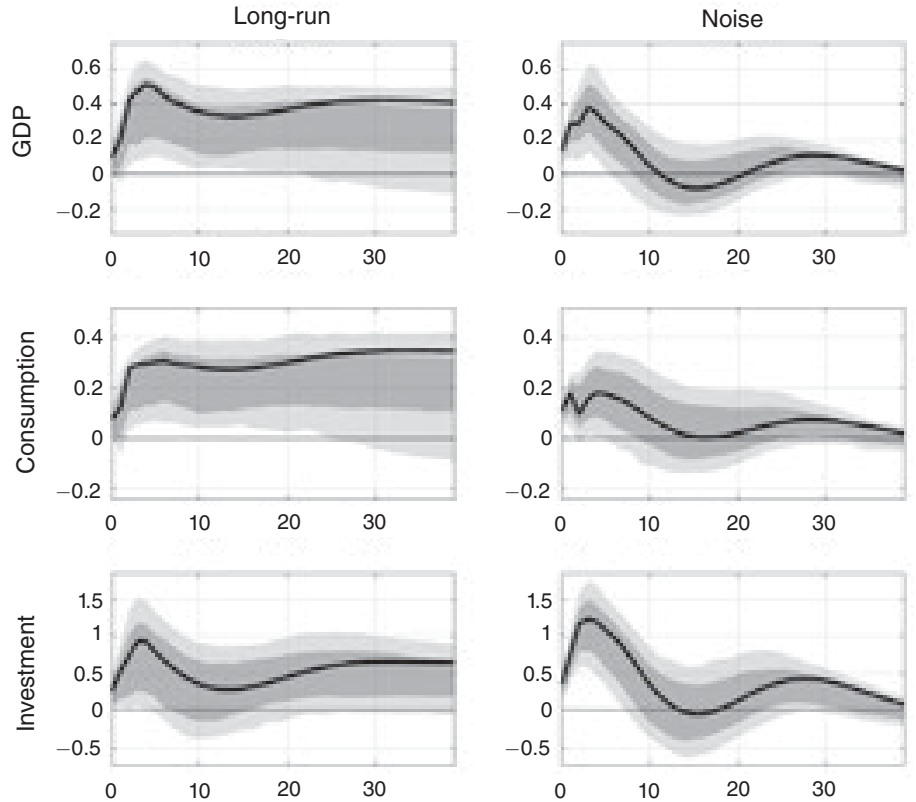

Figure 7. Impulse-Response Functions to Long-Run and Noise Shocks, Specification I

Notes: Impulse response functions to long-run (left column) and noise (right column) shocks with Specification I. Solid line: point estimate. Light gray area: 90 percent confidence bands. Dark gray area: 68 percent confidence bands.
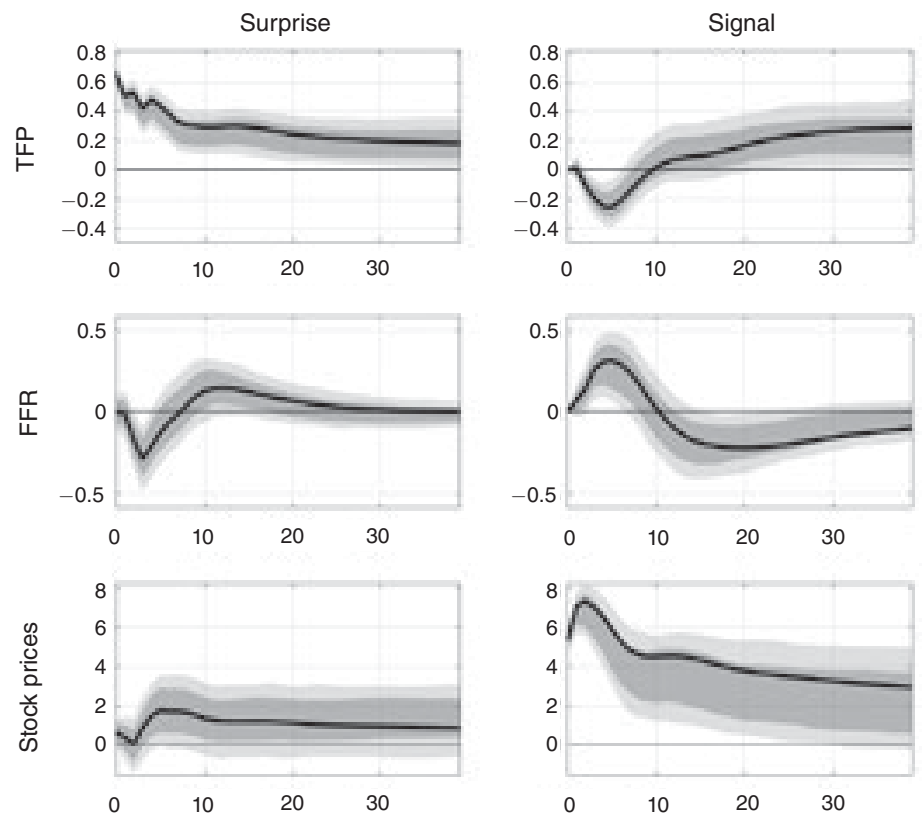

Figure 8. Impulse-Response Functions to Surprise and Signal Shocks, Specification II

Notes: Impulse response functions to surprise (left column) and signal (right column) shocks with Specification II. Solid line: point estimate. Light gray area: 90 percent confidence bands. Dark gray area: 68 percent confidence bands. 

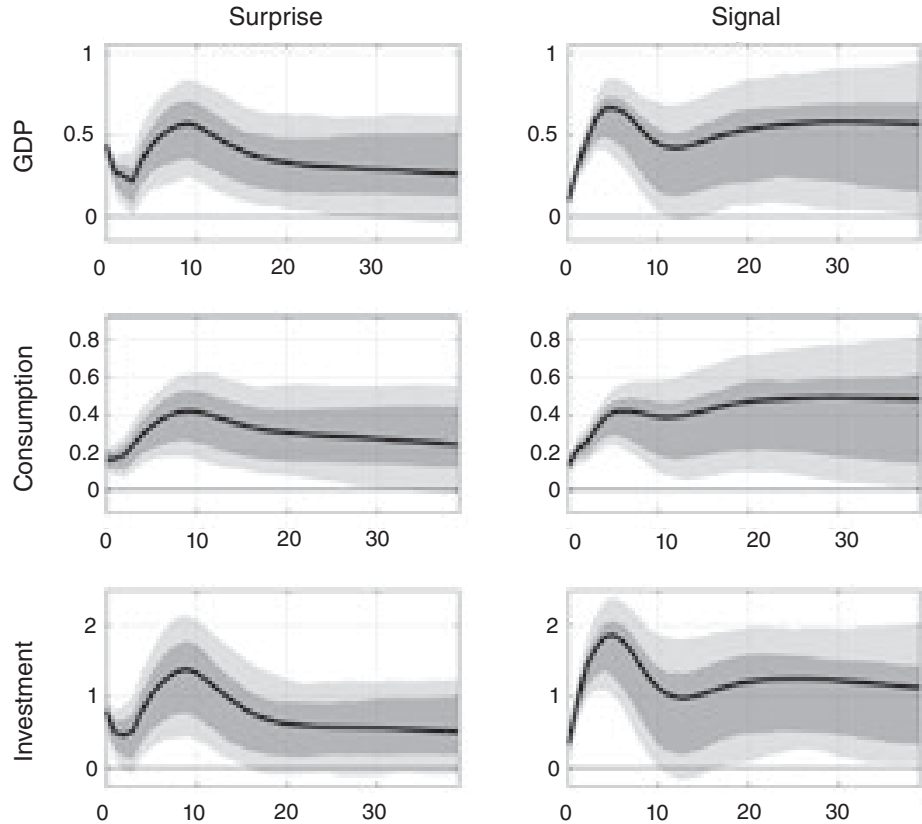

Figure 9. Impulse-Response Functions to Surprise and Signal Shocks, Specification II

Notes: Impulse response functions to surprise (left column) and signal (right column) shocks with Specification II. Solid line: point estimate. Light gray area: 90 percent confidence bands. Dark gray area: 68 percent confidence bands.
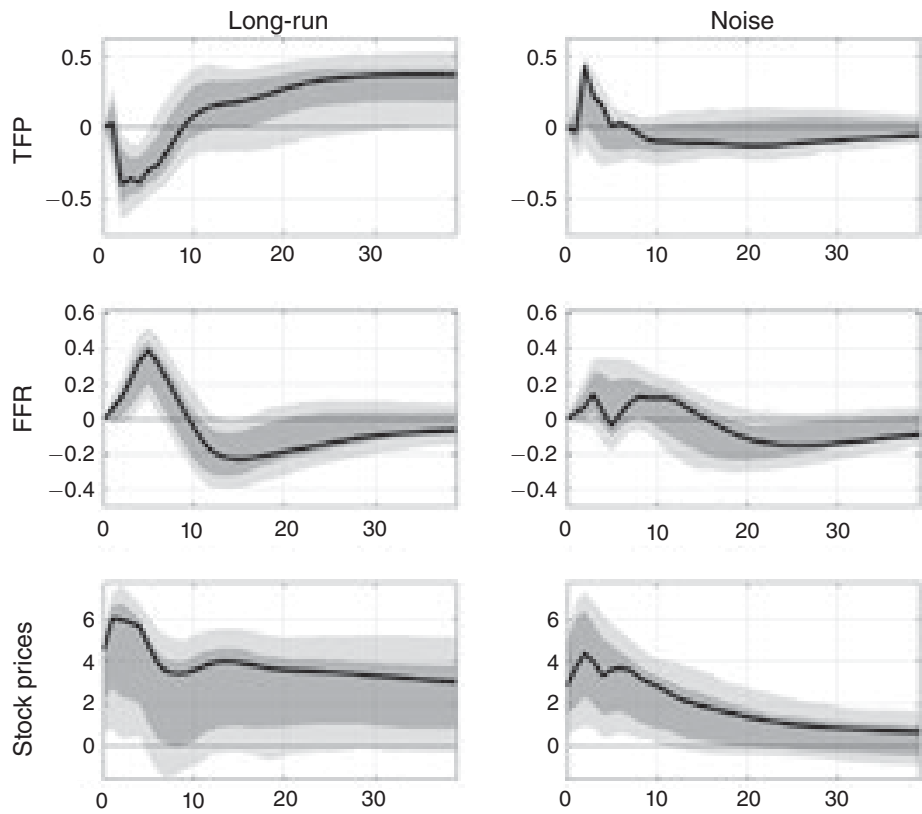

Figure 10. Impulse-Response Functions to Long-Run and Noise Shocks, Specification II

Notes: Impulse response functions to long-run (left column) and noise (right column) shocks with Specification II. Solid line: point estimate. Light gray area: 90 percent confidence bands. Dark gray area: 68 percent confidence bands. 

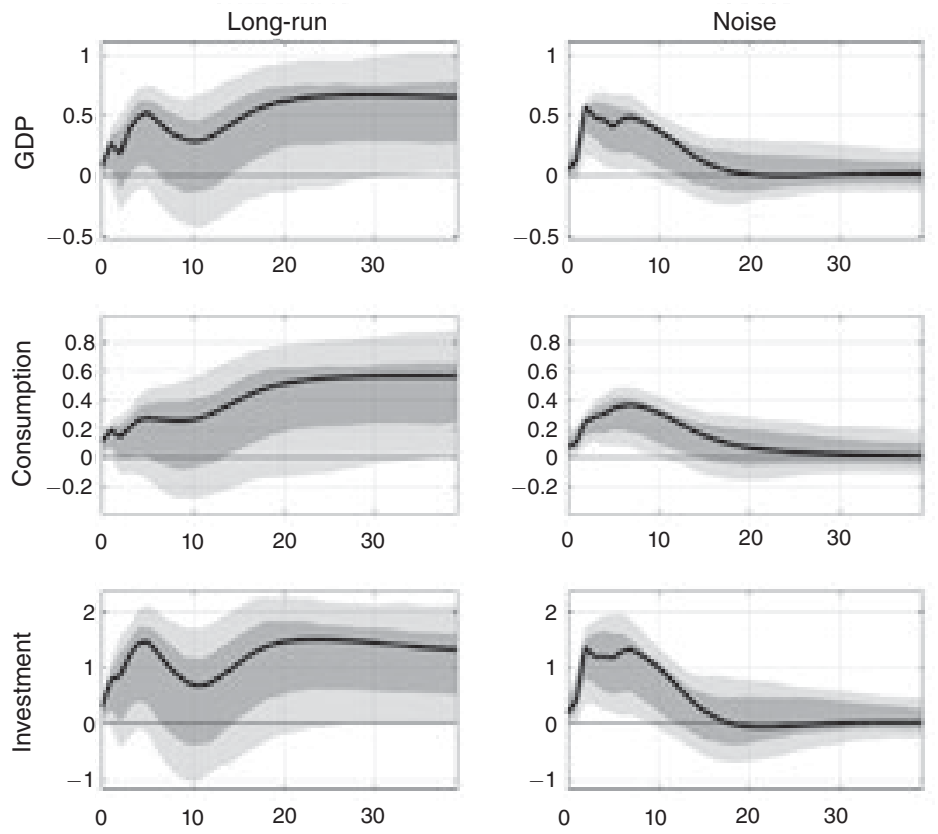

Figure 11. Impulse-Response Functions to Long-Run and Noise Shocks, Specification II

Notes: Impulse response functions to long-run (left column) and noise (right column) shocks with Specification II. Solid line: point estimate. Light gray area: 90 percent confidence bands. Dark gray area: 68 percent confidence bands.

GDP, consumption, and investment react similarly to the long-run and noise shocks in the short run, when agents do not distinguish between them, but after about two years the effects of noise decline gradually and vanish after about four years, whereas the effects of genuine news are permanent.

Changing the reference variable implicitly changes somewhat the very definition of long-run and noise shocks. Here the long-run shock is essentially a technology shock, whereas in Specification I its meaning is broader. In this sense, the differences between Specifications I and II may be to some extent substantive, rather than merely reflecting the use of different measurements for the same phenomenon.

\section{Variance Decomposition}

Variance decompositions for Specifications I and II are reported in Tables 2 and 3, respectively. Let us begin with Specification I (Table 2). The signal shock explains a relatively small fraction of potential output volatility (about 17 percent at the ten-year horizon), but a larger fraction of realized GDP, consumption, and investment (27-37 percent at the two-year horizon). This seems consistent with the general idea that news, while providing an imperfect anticipation of future changes of economic fundamentals, are an important source of business cycle fluctuations.

Turning to the analysis of long-run and noise shocks, business cycle fluctuations are partly driven by noise, which accounts for about 16 percent of the forecast error 
Table 2-Variance Decomposition, Specification I

\begin{tabular}{|c|c|c|c|c|c|}
\hline \multirow[t]{2}{*}{ Variable } & \multicolumn{5}{|c|}{ Horizon } \\
\hline & Impact & 1-Year & 2-Years & 4-Years & 10 -Years \\
\hline & \multicolumn{5}{|c|}{ Surprise } \\
\hline GDPPOT & 100.0 & 93.7 & 84.6 & 67.0 & 42.5 \\
\hline FFR & 0.0 & 2.6 & 4.0 & 3.7 & 4.4 \\
\hline S\&P500 & 0.0 & 0.1 & 0.8 & 4.7 & 11.5 \\
\hline GDP & 9.4 & 7.6 & 9.4 & 17.4 & 22.5 \\
\hline CONS & 17.3 & 9.2 & 9.8 & 17.1 & 24.1 \\
\hline \multirow[t]{2}{*}{ INV } & 0.1 & 0.1 & 0.1 & 0.1 & 4.8 \\
\hline & \multicolumn{5}{|c|}{ Signal } \\
\hline GDPPOT & 0.0 & 1.5 & 7.8 & 17.9 & 17.2 \\
\hline FFR & 0.0 & 6.5 & 7.2 & 10.9 & 20.2 \\
\hline S\&P500 & 99.6 & 94.1 & 91.1 & 72.9 & 45.4 \\
\hline GDP & 7.0 & 36.6 & 37.8 & 30.1 & 25.5 \\
\hline CONS & 9.9 & 23.5 & 27.3 & 27.0 & 25.0 \\
\hline \multirow[t]{2}{*}{ INV } & 6.2 & 33.8 & 30.8 & 24.1 & 26.1 \\
\hline & \multicolumn{5}{|c|}{ Long-run } \\
\hline GDPPOT & 0.0 & 74.7 & 82.3 & 80.9 & 58.1 \\
\hline FFR & 0.0 & 0.6 & 0.8 & 4.0 & 9.7 \\
\hline S\&P500 & 32.3 & 30.8 & 32.2 & 33.6 & 34.3 \\
\hline GDP & 2.5 & 25.7 & 31.4 & 35.5 & 41.8 \\
\hline CONS & 3.9 & 21.5 & 26.6 & 35.6 & 44.8 \\
\hline \multirow[t]{2}{*}{ INV } & 2.0 & 11.6 & 10.4 & 9.0 & 17.0 \\
\hline & \multicolumn{5}{|c|}{ Noise } \\
\hline GDPPOT & 0.0 & 15.4 & 7.5 & 2.4 & 0.4 \\
\hline FFR & 0.0 & 6.9 & 9.6 & 10.6 & 14.7 \\
\hline S\&P500 & 67.3 & 63.3 & 59.7 & 43.6 & 22.2 \\
\hline GDP & 5.2 & 16.4 & 14.3 & 10.4 & 5.5 \\
\hline CONS & 8.1 & 8.7 & 8.7 & 6.6 & 3.4 \\
\hline INV & 4.2 & 22.3 & 20.5 & 15.8 & 13.5 \\
\hline
\end{tabular}

Note: Percentage of the forecast error variance explained by the shocks.

variance of GDP and 22 percent of investment at the one-year horizon. The effect of the long-run shock at the same horizon is somewhat larger for GDP and consumption and smaller for investment.

Noise and long-run shocks together explain about 40-45 percent of GDP fluctuations at horizons ranging from 2 to 4 years. This finding and the fact that the two shocks generate positive co-movements between GDP, consumption, and investment in the short and medium run, drives us to the main conclusion that noisy expectations of future changes in economic fundamentals, which in large part do not eventually materialize, should be considered a major source of business cycles.

Similar results are found with Specification II (Table 3). The surprise shock explains about 30-32 percent of GDP variance at business-cycle horizons. This number is essentially in line with Barsky and Sims (2011) and Forni, Gambetti, and Sala (2014), which find similar figures for an observed news shock, which corresponds here to the signal. The noise shock explains about 20-25 percent of GDP, consumption, and investment at the two-year horizon. The long-run shock explains about 15-20 percent of real variables at the same horizon. As the horizon 
Table 3-Variance Decomposition, Specification I

\begin{tabular}{|c|c|c|c|c|c|}
\hline \multirow[t]{2}{*}{ Variable } & \multicolumn{5}{|c|}{ Horizon } \\
\hline & Impact & 1-Year & 2-Years & 4-Years & 10 -Years \\
\hline & \multicolumn{5}{|c|}{ Surprise } \\
\hline TFP & 100.0 & 78.8 & 70.1 & 61.5 & 46.4 \\
\hline FFR & 0.0 & 6.1 & 9.7 & 10.9 & 19.2 \\
\hline S\&P500 & 1.3 & 1.4 & 3.9 & 4.6 & 3.7 \\
\hline GDP & 59.3 & 13.7 & 18.8 & 25.5 & 17.6 \\
\hline CONS & 13.0 & 13.0 & 19.5 & 25.3 & 18.2 \\
\hline \multirow[t]{2}{*}{ INV } & 22.1 & 7.3 & 13.2 & 19.3 & 16.6 \\
\hline & \multicolumn{5}{|c|}{ Signal } \\
\hline TFP & 0.0 & 6.5 & 9.3 & 7.0 & 21.1 \\
\hline FFR & 0.0 & 6.1 & 9.7 & 10.9 & 19.2 \\
\hline S\&P500 & 98.2 & 92.5 & 88.6 & 81.7 & 57.3 \\
\hline GDP & 2.9 & 30.7 & 32.3 & 31.8 & 37.5 \\
\hline CONS & 8.5 & 21.9 & 25.9 & 30.4 & 38.1 \\
\hline \multirow[t]{2}{*}{ INV } & 4.2 & 34.5 & 34.4 & 32.3 & 41.7 \\
\hline & \multicolumn{5}{|c|}{ Long-run } \\
\hline TFP & 0.0 & 46.3 & 43.9 & 32.7 & 53.1 \\
\hline FFR & 0.0 & 6.1 & 10.8 & 13.8 & 17.1 \\
\hline S\&P500 & 71.5 & 65.7 & 60.1 & 57.8 & 46.1 \\
\hline GDP & 5.0 & 15.4 & 18.6 & 23.6 & 43.8 \\
\hline CONS & 7.0 & 11.5 & 13.3 & 22.5 & 45.2 \\
\hline \multirow[t]{2}{*}{ INV } & 3.8 & 19.6 & 20.3 & 22.3 & 45.2 \\
\hline & \multicolumn{5}{|c|}{ Noise } \\
\hline TFP & 0.0 & 27.2 & 18.0 & 14.1 & 8.8 \\
\hline FFR & 0.0 & 1.0 & 1.2 & 2.1 & 7.1 \\
\hline S\&P500 & 28.0 & 28.2 & 32.2 & 28.0 & 14.3 \\
\hline GDP & 2.0 & 24.3 & 24.0 & 21.7 & 7.8 \\
\hline CONS & 2.7 & 16.1 & 22.0 & 20.4 & 6.7 \\
\hline INV & 1.5 & 19.3 & 21.1 & 19.8 & 10.5 \\
\hline
\end{tabular}

Note: Percentage of the forecast error variance explained by the shocks.

increases, the long-run shock becomes more and more important, whereas the variance explained by noise reduces.

The results on the relative role of long-run and noise shocks differ substantially with what is found in previous literature. First, the role of noise is much larger than in BS, where "animal spirits" have negligible effects. Second, they are qualitatively different from what is found in BLL, where noise explains a very large fraction of consumption fluctuations on impact, a small fraction of consumption variance at the three-year horizon, and almost nothing of investment fluctuations at all horizons. Such large differences call for some explanations. For the reasons explained in Section II, the results of BLL and BS are not obtained by estimating a structural VAR. They specify a theoretical model and estimate the parameters of the model. A shortcoming of such procedure is that it requires strong a priori restrictions on the dynamic responses of the variables to the structural shocks. For instance, BLL assumes that the impulse response function of $\Delta a_{t}$ to the long-run shock is $1 /(1-\rho L)$, whereas BS assumes $L /(1-\alpha L)$. Both models assume that there is a second shock affecting productivity. BS assumes a permanent shock with 
no dynamic at all, whereas BLL assumes a transitory shock with response function $(1-L) /(1-\rho L)$, the parameter $\rho$ being the same as before. Clearly such restrictions are arbitrary to a large extent and may in principle have important effects on the final results. From this point of view, structural VAR methods have the advantage that the dynamic shape of the impulse response functions is essentially unrestricted.

\section{E. Historical Decomposition}

Figure 12 reports the year-over-year growth rates of GDP and the year-over-year growth rates of GDP due to the noise shock estimated with Specification I (top panel) and the year-over-year growth rates of GDP and the year-over-year growth rates of GDP due to the noise shock estimated with Specification II (bottom panel).

A few interesting results emerge. First, we see that during the boom of the late 1990s, the noise is responsible for a large fraction of the growth rate of GDP. Second, the shock substantially contributes to the 2001 recession and the slow recovery of the following two years. The low-pace consumption and investment growth of 2002 and 2003 , according to the picture, was largely attributable to bad signals about future potential output outcomes, which ex-post turned out to be just noise. Between 2004 and 2006, the shock again substantially contributed to the economic expansion. It is interesting to notice that the periods 1997-2000 and 2003-2006 were associated with asset price bubbles. In a companion paper, we show that noise in stock prices explains the information technology boom of the stock market at the end of the 1990 and the subsequent burst (Forni et al. forthcoming).

\section{F. Alternative Proxy for the Signal}

In this subsection, we change Specification I by using $\left(\mathrm{I}^{\prime}\right)$, a different proxy for the signal, and $\left(\mathrm{I}^{\prime \prime}\right)$, a different variable to purge stock prices from short-run fluctuations. In experiment $I^{\prime}$, we replace stock prices with a component of the Michigan consumer sentiment indicator, i.e., expected business conditions within the next five years (E5Y), so that we have GDPPOT, FFR, E5Y, GDP, CONS, and INV. In experiment $\mathrm{I}^{\prime \prime}$, we replace the federal funds rate with the spread between the BAA Corporate Bond rate and the 10-Year Treasury Bond rate, ${ }^{20}$ so that we have GDPPOT, Spread, S\&P500, GDP, Consumption, and Investment. Figures A.1 and A.2 in the online Appendix plot the impulse response to the long-run and the noise shocks obtained with the two new specifications (dashed and starred lines) as well as the point estimate and the confidence bands obtained in the benchmark specification (solid lines and gray areas).

The results for the new specifications are qualitatively similar to those obtained in the benchmark case. For both Specifications I' and I', the responses of GDP, consumption, and investment to the noise shock are somewhat larger and more persistent

\footnotetext{
${ }^{20}$ We have also experimented with the excess bond premium variable constructed in Gilchrist and Zakrajšek (2012). Unfortunately, that variable is available on a shorter sample, from 1973:I to 2010:III. In addition, we tried a specification including both FFR and the spread before stock prices. In both cases results, not shown here, are qualitatively similar to the benchmark.
} 

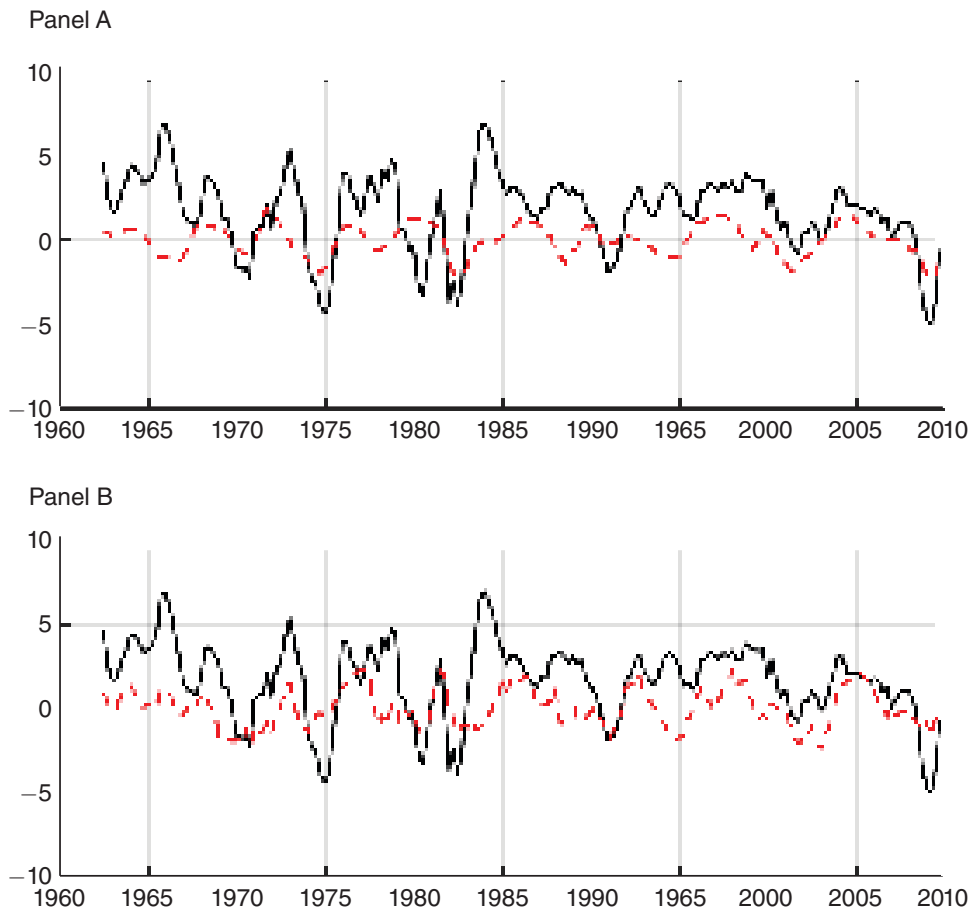

Figure 12. Historical Decompositions

Notes: Panel A: Specification I. Solid line: year-over-year growth rates of GDP. Dashed line: noise component of the year-over-year growth rates of GDP. Panel B: Specification II. Solid line: year-over-year growth rates of GDP. Dashed line: noise component of the year-over-year growth rates of GDP.

than in the benchmark case. With Specification I', noise shocks explain at most 20 percent of GDP fluctuations, the maximum being at the four-year horizon. With Specification I", the maximal explained variance is reached at the two-year horizon: 17 percent for GDP, 19 percent for consumption, and 29 percent for investment.

\section{G. Alternative Identification Scheme}

In this subsection, we take Specification II as the benchmark. We run two experiments. In the former one $\left(\mathrm{II}^{\prime \prime}\right)$ we use the interest rate spread above in place of FFR. In the latter one $\left(\mathrm{II}^{\prime \prime}\right)$ we use the same variables as in the benchmark specification but impose different restrictions to identify the signal. Following Forni, Gambetti, and Sala (2014), we identify the signal by imposing that it does not affect TFP on impact and its effect on TFP at the ten-year horizon is maximal.

Figures A.3 and A.4 in the online Appendix report the impulse response functions of long-run and noise shocks for Specification II' (dashed lines) and Specification II" (starred lines). For comparison, in those figures we report the point estimates and the confidence bands obtained in the benchmark Specification II (solid lines and gray areas). The results of the three VARs are very similar. With Specification II', the signal explains about 29 percent of TFP at the ten-year horizon. The estimated value 
for $\sigma_{v} / \sigma_{s}$ is as small as 0.43 . Despite this, noise explains 30 percent of GDP fluctuations at the one-year horizon. With Specification II", the corresponding figures are 26 percent, 0.50 , and 21 percent, respectively.

\section{H. Alternative Definition of Potential Output}

In this subsection, we go back to Specification I and use a different definition of potential output. Instead of using the CBO measure, we define potential output as a one-sided (backward) moving average of log real per capita GDP. The moving average we use weights equally 32 points in the past. Figures A.5 to A.6 in the online Appendix show impulse responses and confidence bands with Specification I (bold line and gray areas) and with the new definition of potential output (dashed). Results are qualitatively similar to the benchmark.

\section{Conclusions}

In this paper, we have presented a business-cycle model where agents receive imperfect signals about future economic fundamentals. We have shown that in this model the structural MA representation of economic variables is non-fundamental, so that standard structural VAR methods fail. We have argued that this is a general feature of models where economic agents cannot see the structural shocks.

As time goes by, both the agents and the econometrician learn about past structural shocks. A distinguishing feature of our model is that the structural shocks can be recovered exactly from future information. This is because, unlike existing models with imperfect information, the number of structural shocks is equal to the number of independent sources of informations observed by the agents. We have shown that in this case structural VARs can still be successfully used to estimate the structural shocks and the related impulse response functions, provided that identification is generalized to include dynamic transformations of VAR residuals.

In the empirical section, we have estimated a VAR and imposed a dynamic scheme to identify long-run and noise shocks and the related impulse response functions. We have found that noise and long-run shocks together explain a large fraction of the fluctuations of GDP, consumption, and investment at business-cycle horizons. A good deal of such fluctuations are due to noise shocks that generate hump-shaped responses of GDP, consumption, and investment. The role of noise shocks is much larger than in BS, where "animal spirits" have negligible effects, and qualitatively different from BLL, where it explains a very large fraction of consumption fluctuations on impact, but a relatively small fraction of consumption variance at the three-year horizon, and almost nothing of investment fluctuations.

\section{REFERENCES}

Angeletos, George-Marios, and Jennifer La'O. 2010. "Noisy Business Cycles.” In NBER Macroeconomics Annual 2009, Vol. 24, edited by Daron Acemoglu, Kenneth Rogoff, and Michael Woodford, 319-78. Chicago: University of Chicago Press.

- Barsky, Robert B., and Eric R. Sims. 2011. "News shocks and business cycles.” Journal of Monetary Economics 58 (3): 273-89. 
Barsky, Robert B., and Eric R. Sims. 2012. "Information, Animal Spirits, and the Meaning of Innovations in Consumer Confidence." American Economic Review 102 (4): 1343-77.

-Basu, Susanto, John G. Fernald, and Miles S. Kimball. 2006. "Are Technology Improvements Contractionary?" American Economic Review 96 (5): 1418-48.

-Baxter, Brad, Liam Graham, and Stephen Wright. 2011. "Invertible and non-invertible information sets in linear rational expectations models." Journal of Economic Dynamics and Control 35 (3): 295-311.

Beaudry, Paul and Bernd Lucke. 2010. "Letting Different Views about Business Cycles Compete," Vol. 24, edited by Daron Acemoglu, Kenneth Rogoff, and Michael Woodford, 413-55. Chicago: University of Chicago Press.

Beaudry, Paul, Deokwoo Nam, and Jian Wang. 2011. "Do Mood Swings Drive Business Cycles and Is It Rational?" National Bureau of Economic Research (NBER) Working Paper 17651.

Beaudry, Paul, and Franck Portier. 2004. "An exploration into Pigiou's theory of cycles." Journal of Monetary Economics 51 (6): 1183-1216.

-Beaudry, Paul, and Franck Portier. 2006. "Stock Prices, News, and Economic Fluctuations." American Economic Review 96 (4): 1293-1307.

-Blanchard, Olivier J., Jean-Paul L'Huillier, and Guido Lorenzoni. 2013. "News, Noise, and Fluctuations: An Empirical Exploration.” American Economic Review 103 (7): 3045-70.

-Chari, Varadarajan, Patrick J. Kehoe, and Ellen R. McGrattan. 2008. "Are structural VARs with long-run restrictions useful in developing business cycle theory?" Journal of Monetary Economics $55(8): 1337-52$.

Chen, Bin, Jinho Choi, and Juan Carlos Escanciano. 2017. "Testing for fundamental vector moving average representations." Quantitative Economics 8 (1): 149-80.

Christiano, Lawrence, Cosmin Ilut, Roberto Motto, and Massimo Rostagno. 2007. "News Signals: Implications for Business Cycles and Monetary Policy." Paper presented at Macro Seminars Amsterdam, Tinbergen Institute, Amsterdam, May 8.

Cochrane, John H. 1994. "Shocks." Carnegie-Rochester Conference Series on Public Policy 41: 295364.

Coibion, Olivier, and Yuriy Gorodnichenko. 2012. "What Can Survey Forecasts Tell Us about Informational Rigidities?" Journal of Political Economy 120 (1): 116-59.

Den Haan, Wouter J., and Georg Kaltenbrunner. 2009. "Anticipated growth and business cycles in matching models.” Journal of Monetary Economics 56 (3): 309-27.

Dupaigne, Martial, and Franck Portier, 2006. " News' Shocks in International Business Cycles," Society for Economic Dynamics 2006 Meeting Papers 473.

Fernández-Villaverde, Jesús, Juan F. Rubio-Ramírez, Thomas J. Sargent, and Mark W. Watson. 2007. "ABCs (and Ds) of Understanding VARs." American Economic Review 97 (3): 1021-26.

-Forni, Mario, and Luca Gambetti. 2014. "Sufficient information in structural VARs." Journal of Monetary Economics 66 (1): 124-36.

Forni, Mario, Luca Gambetti, Marco Lippi, and Luca Sala. 2017. "Noisy News in Business Cycles: Dataset." American Economic Journal: Macroeconomics. https://doi.org/10.1257/mac.20150359.

Forni, Mario, Luca Gambetti, Marco Lippi, and Luca Sala. Forthcoming. "Noise Bubbles.” Economic Journal.

-Forni, Mario, Luca Gambetti, and Luca Sala. 2014. "No News in Business Cycles.” Economic Journal 124 (581): 1168-91.

Forni, Mario, Luca Gambetti, and Luca Sala. 2016. "VAR Information and the Empirical Validation of DSGE Models.” Centre for Economic Policy Research (CEPR) Discussion Paper 11178.

-Forni, Mario, Domenico Giannone, Marco Lippi, and Lucrezia Reichlin. 2009. "Opening the Black Box: Structural Factor Models with Large Cross Sections.” Econometric Theory 25 (5): 1319-47.

-Giannone, Domenico, and Lucrezia Reichlin. 2006. "Does Information Help Recovering Structural Shocks from Past Observations?" Journal of the European Economic Association 4 (2-3): 455-65.

-Gilchrist, Simon, and Egon Zakrajšek. 2012. "Credit Spreads and Business Cycle Fluctuations." American Economic Review 102 (4): 1692-1720.

Hansen, Lars Peter, and Thomas J. Sargent. 1991. “Two Difficulties in Interpreting Vector Autoregressions." In Rational Expectations Econometrics. Underground Classics in Economics, edited by Lars P. Hansen and Thomas J. Sargent, 77-119. Boulder: Westview Press.

DJaimovich, Nir, and Sergio Rebelo. 2009. "Can News about the Future Drive the Business Cycle?" American Economic Review 99 (4): 1097-1118.

Keynes, John Maynard. 1936. The General Theory of Employment, Interest, and Money. London: Palgrave Macmillan.

Kilian, Lutz. 1998. "Small-Sample Confidence Intervals for Impulse Response Functions." Review of Economics and Statistics 80 (2): 218-30. 
Leeper, Eric M., Todd B. Walker, and Shu-Chun Susan Yang. 2013. "Fiscal Foresight and Information Flows." Econometrica 81 (3): 1115-45.

Lippi, Marco, and Lucrezia Reichlin. 1993. “The Dynamic Effects of Aggregate Demand and Supply Disturbances: Comment." American Economic Review 83 (3): 644-52.

-Lippi, Marco, and Lucrezia Reichlin. 1994. "VAR analysis, nonfundamental representation, blaschke matrices." Journal of Econometrics 63 (1): 307-25.

-Lorenzoni, Guido. 2009. "A Theory of Demand Shocks." American Economic Review 99 (5): 2050-84.

Lorenzoni, Guido. 2010. "Optimal Monetary Policy with Uncertain Fundamentals and Dispersed Information." Review of Economic Studies 77 (1): 305-38.

Lucas, Robert E., Jr. 1972. "Expectations and the neutrality of money." Journal of Economic Theory 4 (2): 103-24.

-Mankiw, N. Gregory, and Ricardo Reis. 2002. "Sticky Information versus Sticky Prices: A Proposal to Replace the New Keynesian Phillips Curve.” Quarterly Journal of Economics 117 (4): 1295-1328.

-Mertens, Karel, and Morten O. Ravn. 2010. "Measuring the Impact of Fiscal Policy in the Face of Anticipation: A Structural VAR Approach.” Economic Journal 120 (544): 393-413.

Pigou, A. C. 1927. Industrial Fluctuations. London: Macmillan.

Rozanov, Yu. A. 1967. Stationary Random Processes. Holden-Day Series in Time Series Analysis. San Francisco: Holden-Day.

-Schmitt-Grohé, Stephanie, and Martín Uribe. 2012. "What's News in Business Cycles." Econometrica 80 (6): 2733-64.

-Sims, Christopher A. 2003. "Implications of rational inattention." Journal of Monetary Economics 50 (3): 665-90.

Woodford Michael. 2002. "Imperfect Common Knowledge and the Effects of Monetary Policy." In Knowledge, Information, and Expectations in Modern Macroeconomics: In Honor of Edmund S. Phelps, edited by Philippe Aghion, Roman Frydman, Joseph E. Stiglitz, et al., 25-58. Princeton: Princeton University Press. 


\section{This article has been cited by:}

1. Joshua C. C. Chan, Eric Eisenstat, Gary Koop. 2020. Choosing between identification schemes in noisy-news models. Studies in Nonlinear Dynamics \& Econometrics, ahead of print. [Crossref]

2. Luca Benati, Joshua Chan, Eric Eisenstat, Gary Koop. 2020. Identifying noise shocks. Journal of Economic Dynamics and Control 111, 103780. [Crossref]

3. RICCARDO M. MASOLO, ALESSIA PACCAGNINI. 2019. Identifying Noise Shocks: A VAR with Data Revisions. Journal of Money, Credit and Banking 51:8, 2145-2172. [Crossref]

4. Ren Zhang. 2019. News Shocks and the Effects of Monetary Policy. SSRN Electronic Journal . [Crossref]

5. Mikkel Plagborg-M\{ø\}ller. 2019. Bayesian inference on structural impulse response functions. Quantitative Economics 10:1, 145-184. [Crossref]

6. Francesco Cordoni, Fulvio Corsi. 2019. Identification of Overdetermined and Noisy Structural VAR Models: The Collapsing-ICA Approach. SSRN Electronic Journal . [Crossref]

7. Ryan Chahrour, Kyle Jurado. 2018. News or Noise? The Missing Link. American Economic Review 108:7, 1702-1736. [Abstract] [View PDF article] [PDF with links]

8. Vegard Larsen, Leif Anders Thorsrud. 2018. Business Cycle Narratives. SSRN Electronic Journal . [Crossref]

9. Dan Cao, Jean-Paul L'Huillier. 2017. Technological Revolutions and the Three Great Slumps: A Medium-Run Analysis. SSRN Electronic Journal . [Crossref]

10. Ryan Chahrour, Kyle Jurado. 2017. Recoverability. SSRN Electronic Journal . [Crossref]

11. Alessia Paccagnini. 2017. Dealing with Misspecification in DSGE Models: A Survey. SSRN Electronic Journal . [Crossref] 